\title{
Agencia y pobreza en la población económicamente activa mexicana
}

María Teresa Herrera Rendón Nebel y Miguel Ángel Díaz Carreño
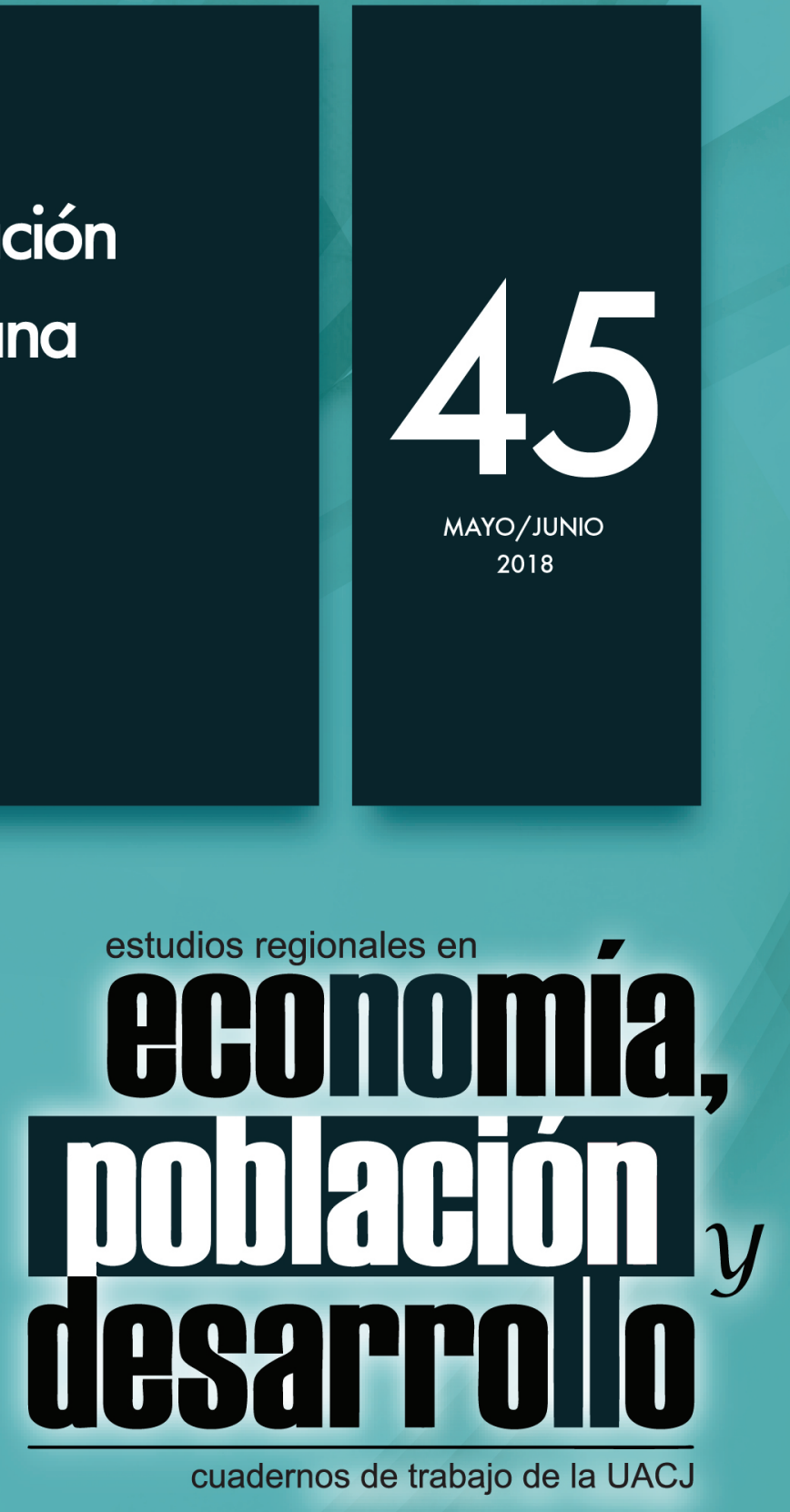


\title{
Agencia y pobreza en la población económicamente activa mexicana
}

\author{
María Teresa Herrera Rendón Nebel y Miguel Ángel Díaz Carreño
}




\title{
UNIVERSIDAD AUTÓNOMA DE CIUDAD JUÁREZ \\ Instituto de Ciencias Sociales y Administración
}

\author{
Cuerpo Académico de Estudios Regionales en \\ Economía, Población y Desarrollo
}

Lic. Ricardo Duarte Jáquez

Rector

M.C. David Ramírez Perea

Secretario General

Mtro. Juan Ignacio Camargo Nassar

Director del Instituto de Ciencias

Sociales y Administración

Mtro. Ramón Chavira Chavira

Director General de Difusión

Cultura y Divulgación Científica

Dr. Luis Enrique Gutiérrez Casas

Coordinador General de

Investigación y Posgrado

\section{Dr. Jaime Alberto Arellano Quiroga \\ Coordinador del Cuerpo Académico de \\ Estudios Regionales en Economía, Población y Desarrollo}

Director y editor

Dr. Luis Enrique Gutiérrez Casas

Comité editorial

Sección internacional

Dra. Sofía Boza Martínez (Universidad de Chile, Chile)

Dra. Olga Biosca Artiñano (Glasgow Caledonian

University, Reino Unido)

Dra. Ángeles Sánchez Díez (Universidad Autónoma de

Madrid, España)

Dr. Thomas Fullerton Mankin (University of Texas at

E1 Paso, Estados Unidos)

Dr. Adrián Rodríguez Miranda (Universidad de la

República, Uruguay)

Sección local

(Universidad Autónoma de Ciudad Juárez)

Dra. Myrna Limas Hernández

Dra. Ikuho Kochi

Dr. Raúl Alberto Ponce Rodríguez

Dr. Isaac Leobardo Sánchez Juárez

Dr. Héctor Alonso Barajas Bustillos

Diseño de cubierta Abigail Bautista
Estudios Regionales en Economía, Población

y Desarrollo. Cuadernos de Trabajo de la UACJ

ISSN 2007-3739

Número 45. Mayo/Junio 2018

Agencia y pobreza en la población

económicamente activa mexicana

María Teresa Herrera Rendón Nebel y

Miguel Ángel Díaz Carreño

Universidad Autónoma de Ciudad Juárez

Estudios Regionales en Economía, Población y Desarrollo. Cuadernos de Trabajo de la UACJ

Año 8, No. 45 mayo - junio 2018, es una publicación bimestral editada por la Universidad Autónoma de Ciudad Juárez a través del Cuerpo Académico de Estudios Regionales en Economía, Población y Desarrollo del Instituto de Ciencias Sociales y Administración. Redacción: Avenida Universidad y H. Colegio Militar, Zona Chamizal s/n., C.P. 32300, Ciudad Juárez, Chihuahua, México. Teléfonos: (656) 688-38-00, ext. 3792. Correo electrónico: lgtz@uacj.mx.

Editor responsable: Luis Enrique Gutiérrez Casas. Reserva de derechos al uso exclusivo No. 04-2011-021713353900-102. ISSN 2007-3739, Impresa por Studio Los Dorados, calle Del Campanario, número 820-2, Santa Cecilia, C.P. 32350, Cd. Juárez, Chihuahua. Distribuidor: Subdirección de Gestión de Proyecto y Marketing Editorial. Ave. Plutarco Elías Calles 1210, Foviste Chamizal, C.P. 32310, Ciudad Juárez, Chihuahua. Este número se terminó de imprimir el 15 de abril, 2018 con un tiraje de 120 ejemplares.

Los ensayos publicados son responsabilidad exclusiva de sus autores. Se autoriza la reproducción total o parcial bajo condición de citar la fuente.

\section{Registrada en:}

Publicación afiliada a la Red Iberoamericana de Estudios del Desarrollo

Universidad Autónoma de Ciudad Juárez

Ave Plutarco Elías Calles 1210

Foviste Chamizal, C.P. 32310

Ciudad Juárez, Chihuahua, México

www.uacj.mx

(C) Universidad Autónoma de Ciudad Juárez 


\title{
Agencia y pobreza en la población económicamente activa mexicana
}

\author{
María Teresa Herrera Rendón Nebel* y \\ Miguel Ángel Díaz Carreño**
}

\begin{abstract}
Resumen
En esta investigación se subraya la importancia de la libertad de agencia para mejorar los niveles de pobreza en la población económicamente activa mexicana. Consideramos que la libertad de agencia es una condición básica para reducir la pobreza y mejorar el bienestar en nuestra sociedad. Hemos elegido un espacio particular en el cual se desenvuelven 54,696,638 personas en México, que conforman el mundo de la población económicamente activa. Tomamos como proxy de libertad de agencia a la responsabilidad, dentro de sus tres categorias: responsabilidad anterior (ex-ante), responsabilidad posterior (ex-post) y responsabilidad autrui (ex-aliud). Los resultados muestran que en México hace falta responsabilidad autrui por parte de las instituciones y empresas y responsabilidad posterior del trabajador. Los bajos niveles en estos dos tipos de responsabilidad no permiten avanzar ni en el mejoramiento de las condiciones de empleo ni en los niveles de pobreza de los trabajadores no cualificados.
\end{abstract}

Palabras clave: Agencia, capacidades, pobreza, empleo, responsabilidad.

\begin{abstract}
This research highlights the relevance of agency liberty to improve poverty levels in the Mexican economically active population. The agency liberty is consider as a basic condition in order to reduce poverty and improve wellbeing in our society. We have chosen a particular space in which 54,696,638 Mexicans part of the economically active population participate. It is used as proxy of agency liberty, the responsibility in three categories: ex-ante responsibility, ex-post responsibility and ex-aliud responsibility. The results show the lack of ex-aliud responsibility in Mexico, with respect to institutions and enterprises, and with respect to workers the lack of ex-post responsibility. This deficiency does not allow to advance or improve labor conditions or poverty levels in less qualified workers.
\end{abstract}

Keywords: Agency, Capabilities, Poverty, Responsibility, Employment. JEL Classification: I31, I39, J88.

- Recibido en: Marzo de 2018.

- Aprobado en: Mayo de 2018.

\footnotetext{
* Profesora investigadora de la Universidad Popular Autónoma de Puebla, México.

Correo electrónico: mariateresa.herrera@upaep.mx.

** Profesor investigador de la Universidad Autónoma del Estado de México, México.

Correo electrónico: madiaz@colpos.mx.
} 


\section{$\rightarrow$ 1. Introducción. ${ }^{1}$}

En esta investigación se subraya la importancia de la libertad de agencia para mejorar los niveles de pobreza de la Población Económicamente Activa (PEA) mexicana. Nos hemos querido concentrar en esta población de "trabajadores" por ser habitualmente descuidada por informes de pobreza a pesar de su importancia tanto económica como numérica. Según datos de INEGI de 2017 la PEA abarca cerca de 55 millones de personas.

Algunos autores, han enfatizado que en México existe indiscutiblemente una precariedad en el empleo, que se manifiesta de diversas formas: bajos salarios, bajas prestaciones, jubilaciones precarias, pobreza, etc (CEPAL, 2011, Rösner H. J, 2012). Parece por lo tanto relevante estudiar cómo mejorar el bienestar de este sector de la población.

La libertad de agencia dentro del enfoque de capabilidades puede ser considerada como una meta-capabilidad que condiciona el acceso a las demás capabilidades. Por esto, hemos propuesto (Nebel \& Herrera 2017) de considerarla como un punto focal de máxima importancia para reducir la pobreza y mejorar el bienestar de una población.

Este trabajo retoma por lo tanto las aportaciones de medición de la cualidad de la agencia, que hicimos en 2017 (Nebel y Herrera, 2017, Herrera, Nebel y Díaz, 2017). En estos trabajos, la medición de la meta-capabilidad de agencia se hizo por medio del concepto de responsabilidad desglozado en sus tres categorías: responsabilidad anterior (ex-ante), responsabilidad posterior (ex-post) y responsabilidad autrui (ex-aliud). Los resultados obtenidos indican que la cualidad de la agencia no se da de manera uniforme en una población - contrariamente a lo que presupone Rawls - y que además resulta de doble componente: propia a cada individuo (positive freedom) y condicionada por el contexto social (negative freedom). Estas variaciones de la libertad de agencia en una población son sumamente importantes ya que privado de libertad de agencia, un individuo deja de valorar su propia libertad.

Este documento se divide de la siguiente manera, primero explicamos la diferencia que hace Amartya Sen entre libertad de agencia y libertad de bienestar, después vemos la importancia de medir la libertad de agencia, en lugar de medir las carencias de la población como lo hace el Consejo Nacional de Evaluación de la Política Social (CONEVAL). Para ello seguiremos usando como proxy de agencia a la responsabilidad. Más adelante se ve cuáles son los niveles de responsabilidad en México considerando un contexto muy particular, que es el contexto laboral, en seguida, analizamos los niveles de responsabilidad considerando algunos grupos de personas particulares de la población mexicana y finalmente se presentan las conclusiones.

1 Agradecemos aquí el apoyo invaluable del Departamento de Investigación y de Encuestas del INEGI, sin el cual éste trabajo no hubiera sido posible. Así como los comentarios del Dr. Mathias Nebel a éste artículo. 


\section{La pobreza en el enfoque de capabilidades.}

Tal como se menciona en Nebel, M., Flores-Crespo, P., Herrera R. Nebel, M.T. (2014) y como lo han subrayado diversos estudiosos del enfoque de capabilides, Sen (1992) considera que el desarrollo económico está íntimamente ligado al crecimiento de la libertad efectiva de la cual gozan las personas. En otras palabras, para el enfoque de capabilidades el bienestar es visto como una maximización de libertades y su anti-tesis, la pobreza, como una carencia de éstas.

A diferencia del punto de vista tradicional, que explica que la pobreza se debe exclusivamente a una falta de ingresos, el enfoque de capabilidades lo ve como un fenómeno multidimensional:

"Si el desarrollo humano trata de aumentar las opciones de las personas, la pobreza significa que las oportunidades y opciones más básicas del desarrollo humano son negadas -vivir una vida larga, saludable y creativa y disfrutar de un estándar decente de vida, libertad, autoestima y estima por los otros" (Fukuda \& Kumar, 2003, 38).

El reporte del Programa de las Naciones Unidas para el Desarrollo (PNUD) de 2003, como vimos en la cita anterior de Fukuda \& Kumar, resume la pobreza como la privación de capabilidades, juzgando así al desarrollo en función de la situación de las personas. Un bajo nivel de desarrollo está asociado a un alto nivel de carencias de las personas en una sociedad.

Así pues, la pobreza es interpretada en esta cita del PNUD como la imposibilidad de alcanzar logros mínimos en las distintas capabilidades fundamentales (vivir hasta la edad promedio, gozar de buena salud, ser capaz de alimentarse decentemente, etc.). Recientemente, se ha subrayado la importancia de incluir otros elementos en el Índice de Desarrollo Humano (IDH), como el empoderamiento, la dimensión étnica, las diferencias de sexo, etc. (PNUD, 2004, 2010, 2015).

Sin embargo, hasta hoy el IDH ha medido sólo la libertad de bienestar a través de las capabilidades of funcionamientos, pero poca importancia se le ha dado a la libertad de agencia. Sin embargo, de esta depende la capacidad del individuo para transformar medios en logros lo que Robeyns (2005:98) llama "los factores personales de conversión" - es central dentro de esta perspectiva, ya que determina o determinan la habilidad para convertir medios (tales como el ingreso y bienes primarios), en capabilidades de acuerdo con las características del individuo. Como veremos, el resultado no será el mismo para todos los individuos y dependerá de sus propias capacidades y de su contexto social. En otras palabras, aquí se consideran aspectos materiales e inmateriales, como el acceso efectivo a bienes y servicios (mercancías, relaciones sociales, acceso a bienes púbicos, situación cultural y demográfica, nivel de educación, etc.).

El mismo Sen (2000), considera que una persona pobre es aquella que no puede desarrollar actividades importantes que podría desear hacer. Por tanto, se ve que hay otros elementos interco- 
nectados a la pobreza, como la exclusión social. Según Sen, la forma de ver la pobreza, debe ser enriquecida justamente por el enfoque de la exclusión social. En sus orígenes, la exclusión social se asociaba a aquellas personas o sectores que no tenían acceso a los beneficios del Estado (Arim y Vigorito, 2014). Barry (1998) considera que los individuos o grupos que están socialmente excluidos son aquellos a los que se les niega la oportunidad de participación, independientemente de si ellos quieren o no participar. Barry distingue dos umbrales, el bajo y el alto. El primero divide a quienes participan comúnmente en las instituciones y quienes no lo hacen por estar excluidos. El segundo separa a los sectores medios de los sectores que pueden separarse de las instituciones y deciden aislarse.

Para Sen es evidente que hay una relación estrecha entre exclusión social y pobreza, pues la exclusión social puede ser un aspecto constitutivo de la pobreza, en tanto que se refiere a la privación de la posibilidad de vivir una vida que uno tiene razones para valorar. Nosotros vemos aquí, a la pobreza y/o exclusión social como manifestaciones de la falta de la cualidad de agencia en una sociedad determinada.

Como hemos visto más arriba, la multidimensionalidad de la pobreza no se resume a ingreso, bienes primarios, salud, vivienda, felicidad, esperanza de vida y educación, estas son manifestaciones de la pobreza. Más aún si nos concentramos en el caso de México, como en el resto de los países de América Latina, existen muchos aspectos particulares de la historia y cultura del continente que, a nuestro parecer, estigmatizan nuestra pobreza, tanto a nivel continental, como nacional o local. Intervienen en la pobreza elementos como identidades culturales (mestizos-indígenas), relaciones entre géneros (machismo, masculinidad), legislaciones (eficiencia de la justicia, acceso e impunidad), participación democrática, clases sociales (exclusión/inclusión), práctica del poder (caciquismo, clientelismo, corrupción, asimetrías), creencias religiosas, etc. Así pues, creemos que estudios concentrados en la libertad de agencia pueden interpretar mejor el origen de estas carencias.

\section{La agencia condición básica para mejorar el bienestar en el enfoque de capabilidades.}

Sen, en diversas ocasiones, menciona que el bienestar es visto como la maximización de la libertad. ¿Y de qué libertad habla Sen? en sus trabajos se puede ver que Sen distingue dos tipos de libertad: la libertad de agencia y la libertad de bienestar (Sen, 1985:185-187). "La libertad de agencia, de la cual dispone un individuo, es la que le permite llevar a término lo que busca, valora y se propone realizar; mientras que la libertad de bienestar considera únicamente su libertad para buscar lo que

2 Sen, 1992, p. 88.

- Economía, Población y Desarrollo. Cuadernos de Trabajo de la UACJ, núm. 45, may-jun 2018 
constituye su bienestar propio." " La libertad de bienestar puede ser medida a través de las capabilidades es decir de los seres y haceres (tener buena salud, tener acceso a la educación, tener acceso al agua potable, etc.), pero medir libertad de agencia es menos evidente.

La libertad de agencia considera al individuo como un ser que formula juicios sobre su propio bienestar y es capaz de tomar decisiones que le permiten emanciparse y participar en la vida política, es decir, adquiere control sobre su propia existencia. Así concebido, el agente es un ser autónomo y responsable, capaz de elegir ${ }^{3}$, y no aquel individuo incapaz de concebir lo que tiene que ser su vida y como debe conducirla (Bertin, A. 2014:421). Así pues, la posesión de lo que Sen llama la cualidad de agencia, le permite al individuo renunciar incluso a su propio bienestar o libertad. Cuando se busca el bienestar de los hijos en lugar del bienestar propio, por ejemplo, o bien cuando se elige morir por otros o cuando se renuncia a la libertad a causa de la dependencia a la droga, al alcoholismo, la pornografía etc.

Sen advierte que la libertad de agencia es importante, pero a él le interesa concentrarse en la libertad de bienestar y entonces el enfoque de capabilities se focaliza en las capabilidades y entonces lo que se mide son carencias: carencia de agua, carencia de ingreso, carencia de educación, carencia de salud, etc. Pero al medir carencias, como lo hace CONEVAL en México o el Índice de desarrollo humano (IDH), no buscamos el origen de estas carencias y por lo tanto no podemos dar soluciones adecuadas ni enfocar debidamente los programas de combate contra la pobreza.

Crocker (2009), Ronill (2004), Cortina (2007), Crocker (2009), y Nebel y Herrera R. N (2017) en contra partida, subrayan la importancia de la cualidad de la agencia, diciendo que juega un papel determinante en el bienestar individual y colectivo. Incisitiendo que mayor atención tendríamos que darle a esta categoría del enfoque. Estos autores sostienen que existe no solo una relación intrínseca entre la cualidad de agencia y bienestar, sino que enfatizan la superioridad de la primera sobre la segunda, la cualidad de agencia es vista como una meta-capabilidad que ésta por arriba del resto de las capabilidades. Y a pesar de que Sen excluye que la adquisición de la libertad sea un proceso, es decir un aprendizaje y una elección por parte del individuo nosotros siguiendo a Crocker argumentamos que la agencia no es una cantidad fija en nosotros, sino una facultad que se ha desarrollado a lo largo de nuestra existencia. Así pues, le damos a la agencia un sentido más dinámico, ya que la agencia es el fruto de un aprendizaje, es el resultado de un trabajo sobre nosotros mismos. Mi cualidad de agente no es por lo tanto un bien que pudiera considerarse como adquirido pasado una cierta edad, ha de realizarse a través del largo proceso que lleva a un niño a ser adulto y después a ser anciano. Estas constataciones fueron subrayadas por Bonvin y Farvaque (2004) en una crítica a la dotación de bienes primarios de Rawls, decían que una igualdad en la repartición de bienes primarios no asegura una igualdad de oportunidades, ésta última depende de los talentos naturales de cada individuo.

3 Sen, 1985.

- Economía, Población y Desarrollo. Cuadernos de Trabajo de la UACJ, núm. 45, may-jun 2018 
Más aún algunos autores como Conill (2004) \& Cortina (2008) y Crocker (2009) insisten en que la cualidad de la agencia tiene una prioridad normativa sobre las demás capabilidades y por ende sobre la consecución del bienestar. Ballet, Bazin, Dubois \& Mahieu $(2007 ; 2008 ; 2014)$ por su parte sostienen que la capabilidad de agencia se manifiesta en la forma en la cual individuos actúan de manera responsable. Dicho de otro modo, la valoración que dan a su libertad aparece en la forma en la cual desprenden sus responsabilidades (Nebel y Herrera: 2017). Finalmente, Robeyns (2004) define a la responsabilidad como la forma en la cual una persona acepta y se compromete en la realización de un fin y/o deber.

Cómo vemos la agencia en claves de responsabilidad, nos permite darle a la libertad de agencia su carácter normativo, elemento indispensable para mejorar bienestar y por lo tanto pobreza.

\section{$\rightarrow$ 4. La responsabilidad como proxy de agencia.}

Nebel y Herrera (2017), subrayan que si quisiéramos medir la cualidad de agencia bien podríamos considerar la capacidad que tiene el ser humano para elegir su propia libertad y justamente la noción de responsabilidad, antes descrita, describe precisamente a la responsabilidad como el proceso de efectuación de la libertad por un sujeto moral; describe la libertad en cuanto es usada por el sujeto como sujeto. Un ejemplo de un individuo que no considera su actuar libremente como un sujeto ético, sería el caso del enriquecimiento ilícito, por ejemplo, a través de la trata de personas, claramente este individuo no posee cualidad de agencia, porque la manera como está manifestando su libertad lo describe como un sujeto anomico, sin responsabilidad y además está impidiendo el alcance del bienestar de otras personas.

La responsabilidad nos dice también cuáles son los fines, deberes y/o obligaciones de un individuo, dentro de sus diferentes ámbitos: social, laboral, familiar, educativo, político etc. La literatura especializada como bien lo ven Nebel y Herrera (2017), nos dice que existen tres tipos de responsabilidades:

(a) La responsabilidad posterior (ex-post): la responsabilidad en tanto mediación de la relación a sí-mismo (en cuanto me reconozco sujeto de una obligación/promesa);

(b) La responsabilidad anterior (ex-ante): la responsabilidad en tanto mediación de la relación a nuestros actos (en cuanto respondemos de ellos);

(c) La responsabilidad autrui (ex-aliud): la responsabilidad en tanto mediación de la relación hacia los demás (el otro que me convoca a la responsabilidad). 
Enseguida describimos cada una de estos tres tipos de responsabilidad retomando las ideas de Nebel y Herrera (2017).

Primero por responsabilidad anterior, entendemos la capacidad del sujeto para asumir obligaciones o compromisos morales. En otras palabras, la responsabilidad que permite a un sujeto comprometerse a futuro ante sí-mismo y otros ${ }^{4}$. Esta responsabilidad es constituida como la contra parte de la obligación kantiana. Frente al imperativo categórico - "itú debes!" - debe de estar un $y^{5}$ que se reconozca capaz de asumir este deber, una persona en otras palabras que responda a la obligación afirmando - "si, yo lo haré". Al deber kantiano corresponde una antropología de la responsabilidad. Así "ser responsable de..." implica la facultad del sujeto para "hacerse responsable". Es esta capacidad del sujeto para asumir el deber que lo constituye como sujeto ético; sin responsabilidad no existe un sujeto moral. Por lo tanto, la responsabilidad no es un adendum posterior que se agregaría ad-extra a un sujeto ya constituido, sino un elemento sine-qua-non de su autonomía. La agencia - en cuanto posibilidad a ser yo autor de mi propia determinación - requiere por lo tanto que se reconozca una responsabilidad anterior; es más, el sujeto en cuanto actúa, actúa moralmente porqué tiene responsabilidad. Esta relación a sí-mismo por medio de la responsabilidad anterior constituye la primera dimensión de la capabilidad de agencia que queremos medir."

La responsabilidad posterior considera la relación que existe entre un acto y un sujeto (Bovens: 1998, 29-31). Empieza por determinar lo que se hizo o lo que se podría hacer, para luego buscar su causa, es decir asignar este acto a una persona como siendo su autor. Es un proceso reconstructivo. Sale de la acción para ponerse en busca de un sujeto que pueda ser designado como su autor. Identifica una persona como teniendo la responsabilidad de tal acto particular, investigando lo que hubo de libertad y de debida prudencia cuando se cometió y responde a la pregunta "yo lo hice”. En otras palabras, considera la relación de un acto - tanto pasado como futuro - a un sujeto para determinar el nivel de libertad con el cual fue/sería cometido. La asignación de una responsabilidad por lo tanto no es meramente casual, pero involucra medir el grado de libertad, conciencia y prudencia con el cual fue cometido (Ballet, Bazin, Dubois \& Mahieu: 2014, 29-31, 35-39).

En su comprensión más común, la responsabilidad posterior tiene un fuerte matiz jurídico-moral. Describe habitualmente el proceso que una instancia exterior - un tribunal, por ejemplo - emprende durante un proceso para atribuir y luego asignar de manera la más objetiva posible la

4 Este párrafo debe mucho al artículo de Paul Ricœur. Ricœur propone pasar del reconocimiento de sí al mantenimiento de sí en la promesa por medio de tres capabilidades que el identifica como fundacionales: la capabilidad de hablar, de actuar y de narrar. Sin embargo, el aporte de este articulo queda críptico si no es leído en referencia a su ética (Ricœur, 1989).

5 Con Paul Ricoeur no pensamos el sujeto como transparente a sí-mismo en la percepción que tiene de sí-mismo, sino ésta percepción pasa por varias mediaciones entre las cuales la figura del otro es de suma importancia. De tal manera que para Ricoeur, la constitución misma de la consciencia propia incluye el rodeo por el otro. 
responsabilidad de algún acontecimiento a un sujeto. Un juez en estos casos investigara los hechos, buscando la justa ponderación del grado de libertad - previsión, preparación, consciencia, pasión, violencia, debida prudencia, etc. - con el cual fue cometido un acto. ${ }^{6}$

Finalmente, por responsabilidad autrui retomamos el concepto de Emmanuel Lévinas (1974; 1982; 1989). Según el filósofo francés la consciencia moral no surge de la conciencia de sí cartesiana. Sino que es la cara del otro - en su alteridad absoluta, no reducible a mí propia subjetividad - que me llama a responder a una exigencia de justicia que me precede absolutamente ${ }^{7}$. La responsabilidad es aquí por lo tanto un llamado desde el otro, cual reivindicación de justicia me precede siempre y que despierta en mí, a modo de respuesta al llamado, mí ser-responsable. Para Lévinas nazco como sujeto ético a partir de este llamado8.

Ahora bien, una persona no está aislada se desenvuelve en diferentes ambientes. Para cumplir con la condición de agencia es necesario que exista responsabilidad en el individuo y en el contexto social donde se desenvuelve (familia, trabajo, escuela, etc.). En otras palabras, nosotros consideramos que la posesión de la cualidad de agencia, se logra cuando se alcanza simultáneamente la responsabilidad dentro del contexto social y responsabilidad individual, condición necesaria sin la cual no es posible mejorar el bienestar.

En la siguiente parte pretendemos ver si en el sector laboral la condición de agencia está dada, considerando como proxy a la responsabilidad.

\section{La responsabilidad en el sector laboral en México.}

Para medir la responsabilidad hemos elaborado cuestionarios que se aplicaron en 2014 a nivel nacional en México junto con la encuesta de hogares (Nebel y Herrera, 2017). Hemos propuesto medir las tres categorías de la responsabilidad enfocándonos en un ámbito particular donde se desenvuelve el individuo, que es el ámbito laboral.

Decíamos más arriba que la responsabilidad no está dada, sin embargo, no podemos decir que una persona es responsable o no lo es, sino que una persona manifiesta tener diferentes grados de responsabilidad.

El ámbito laboral es muy importante a nivel económico ya que, por un lado, es aquí donde se genera el ingreso y éste es un elemento necesario de bienestar. Y por otro, éste sector está confor-

6 La responsabilidad posterior viene habitualmente ligada a la noción moral de prudencia por requerir de un cálculo fino de las posibles consecuencias de un acto. En una situación de conocimiento y de proyecciones finitos (información limitada), se requiere ponderar entre varias opciones y elegir la que mejores resultados alcanza, que menos incertidumbre conlleva, y que no implique daños para terceros. Tal «ética de la responsabilidad» fue propuesta inicialmente por Max Weber, pero fue ampliamente desarrollada por Hans Jonas (1979). Sen, Nussbaum, Cortina, Crocker enfatizan este aspecto de una responsabilidad posterior. 
mado por una población que no puede es insignificante ya que hay 54,696,638 millones de personas que constituyen a la PEA.

En éste contexto existen dos participantes importantes: el empleado (trabajador) y el empleador (empresa). En nuestro artículo de 2017 (Herrera et al. 2017) consideramos la responsabilidad del trabajador (RT) y la responsabilidad de la empresa (RF) ${ }^{9}$. Una empresa es entendida aquí como el lugar donde trabaja una persona, esta puede ser una institución pública o privada o bien una empresa pública o privada.

Para medir la responsabilidad hemos asignado valores entre 0 y 1 . Solo niveles elevados de responsabilidad permiten a una persona ser funcional y son calificadas con un score de 1 . Niveles bajos son disfuncionales o patológicos y son calificadas con un score de 0 .

Las tres modalidades de responsabilidades que hemos distinguidos más arriba describen efectivamente tres formas de relaciones (relación al otro, Responsabilidad autrui; a sí-mismo, Responsabilidad posterior; a sus acciones, Responsabilidad anterior). Hemos estimado que un individuo que no logre alcanzar $75 \%$ dentro de cada una de estas categorías presenta para los demás un riesgo que compromete la cualidad de estas relaciones y por lo tanto su durabilidad. No es posible sustentar una relación sobre el largo plazo en el ámbito profesional con una persona que evade sus responsabilidades a cada rato $(1 / 4)$.

Una persona puede estar en una zona de fragilidad (75-50\%), una zona grave (50-25\%) y una zona claramente disfuncional o patológica (25-0\%). Un ejemplo permite dejar esto claro. Una persona que solo reconocería ser responsable de lo que realmente cometió de vez en cuando (menos de $50 \%$ ) no es funcional en una empresa (institución pública/privada o empresa (pública/privada). De la misma manera quien no es capaz de proyectarse a futuro y ser fiel a lo que se comprometió más del $50 \%$ de las veces constituye un problema para una empresa. Así proponemos, en la gráfica 1, la escala siguiente (cuantitativa/cualitativa) para leer los resultados obtenidos:

7 «Je parle de la responsabilité comme de la structure essentielle, première, fondamentale de la subjectivité. Car c'est en termes éthiques que je décris la subjectivité. L'éthique, ici, ne vient pas en supplément à une base existentielle préalable ; c'est dans l'éthique entendue comme responsabilité que se noue le noud même du subjectif. J'entends la responsabilité comme responsabilité pour autrui, donc comme responsabilité pour ce qui n'est pas mon fait, ou même ne me regarde pas ; ou qui précisément me regarde, est abordé par moi comme visage. » Lévinas, 1982, 91-92.

8 No entiendo aquí discutir la posición de Levinas que es compleja. Sino que adhiero a la reinterpretación de la misma que propone Paul Ricœur en Sí-mismo como otro donde incorpora la alteridad de la cara del otro en la mediación social por la cual el sujeto se reconoce come uno mismo. La alteridad es aquí por lo tanto interiorizada y devuelta al foro interno del sujeto (Ricœur, 1995). Es decir que para Ricœur, esta última dimensión de la responsabilidad es, con las dos anteriores, una de las partes constitutivas de la formación del sujeto ético. La responsabilidad anterior no es por lo tanto cerrada a modo kantiano sobre sí-misma, sino que es fundamentalmente abierta a los otros, porque su constitución pasa necesariamente por la mediación de los otros (Ricœur: 1989, 167-198).

9 Las preguntas elaboradas en el cuestionario, nos dejan ver cuáles son las expectativas de responsabilidad esperadas por la empresa. Y estas son siempre respuestas del punto de vista del trabajador. 
Gráfica 1

\begin{tabular}{|c|c|c|c|}
\hline 0 & 0,25 & 0,5 & 0,75 \\
\hline $0-25 \%$ & 25-50\% & $50-75 \%$ & $75-100 \%$ \\
\hline No funcional & Problemático & Frágil & Funcional \\
\hline
\end{tabular}

Decíamos más arriba que para que podamos decir que tenemos agencia es necesario alcanzar simultáneamente responsabilidad del trabajador y responsabilidad de la empresa, esto lo podemos visualizar en la gráfica 2.

En la gráfica anterior podemos ver que sólo en el punto A, podemos decir que hay agencia y que por lo tanto las empresas y trabajadores que se encuentren por arriba del .75 pueden efectivamente mejorar sus condiciones y aumentar su bienestar. Las empresas que se encuentren por debajo de 0.75 estás generan externalidades negativas, mayor pobreza y son anclas que impiden a los individuos salir de sus condiciones de pobreza. Ya que no tienen ni responsabilidad de la empresa ni responsabilidad del trabajador.

Gráfica 2

\section{Responsabilidad de la empresa (RF) y responsabilidad del trabajador (RT)}

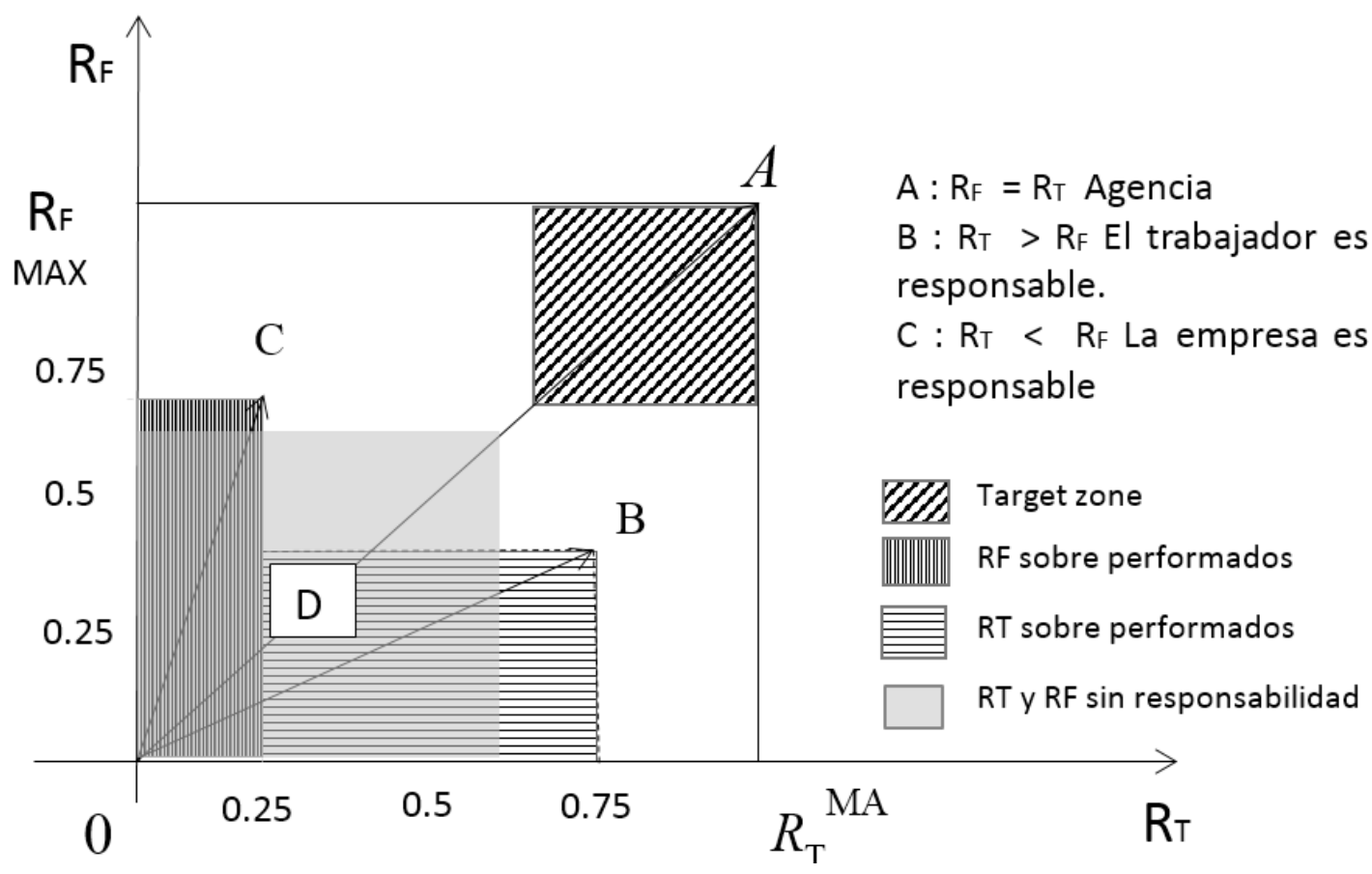


Si aplicamos esta idea a cuatro Estados de la República Mexicana, podemos ver cuáles son las empresas que cumplen simultáneamente con ambas condiciones (ver gráfica No. 3). Lo que podemos ver es que las empresas que aparecen en forma de puntos al interior del cuadro A, son las que cumplen con estas dos condiciones. Los trabajadores que están en éste cuadro A son aquellos que tienen mejores niveles de bienestar. Mientras que los trabajadores que están por debajo de .75 (que están dentro del cuadro D) no cumplen con esta condición, por lo tanto no poseen calidad de agencia. Podemos decir que no es posible que empresas funcionen con niveles tan bajos de responsabilidad a no ser que sean organizaciones envueltas en actividades ilícitas. En el siguiente apartado explicamos estas conclusiones.

Gráfica 2

Responsabilidad de la empresa (RF) y responsabilidad del trabajador (RT)

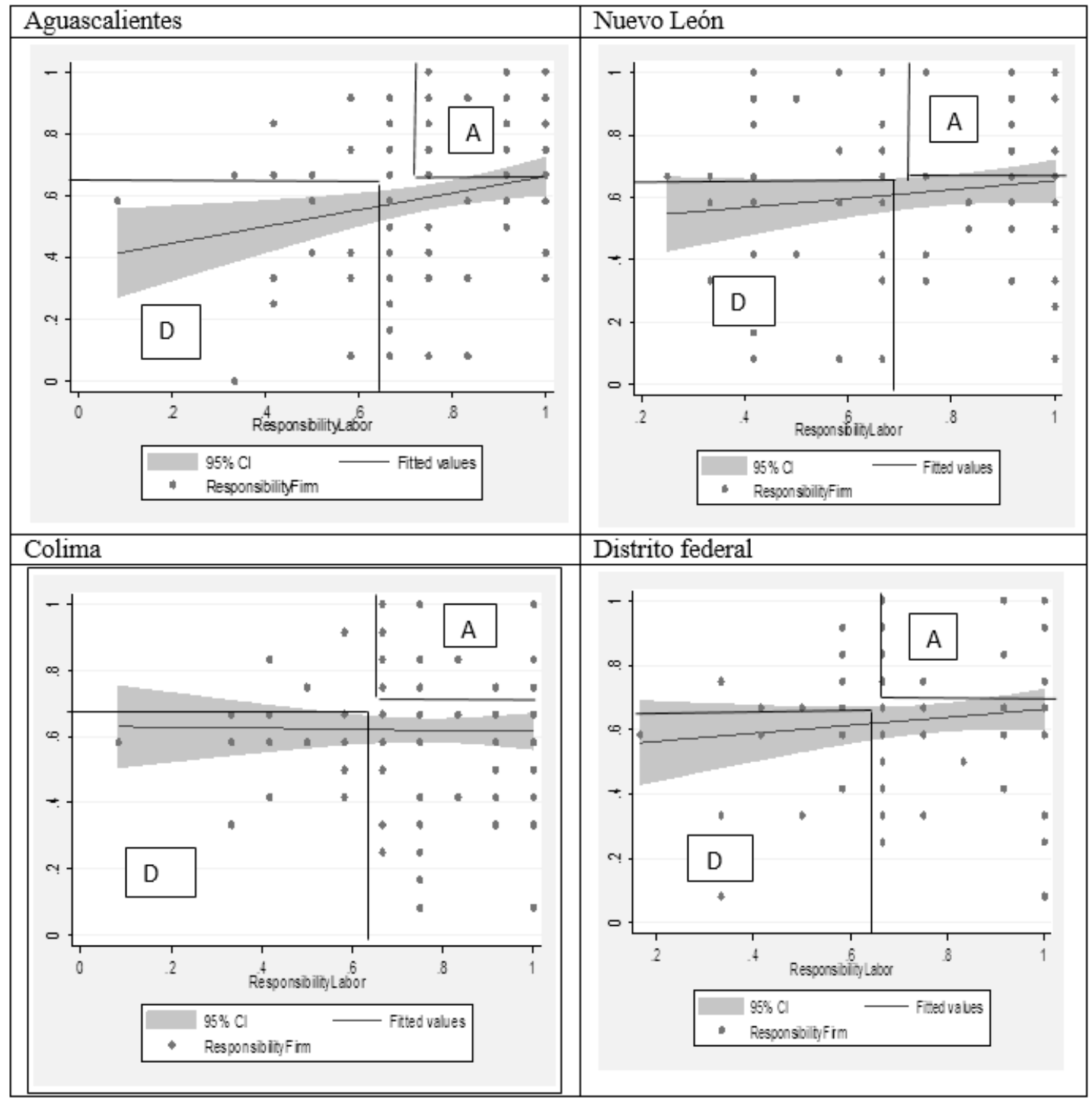

Fuente: INEGI (2014). Encuesta Nacional de Hogares. 
Si aplicamos esta idea a cuatro Estados de la República Mexicana, podemos ver cuáles son las empresas que cumplen simultáneamente con ambas condiciones (ver gráfica No. 3). Lo que podemos ver es que las empresas que aparecen en forma de puntos al interior del cuadro A, son las que cumplen con estas dos condiciones. Los trabajadores que están en éste cuadro A son aquellos que tienen mejores niveles de bienestar. Mientras que los trabajadores que están por debajo de .75 (que están dentro del cuadro D) no cumplen con esta condición, por lo tanto no poseen calidad de agencia. Podemos decir que no es posible que empresas funcionen con niveles tan bajos de responsabilidad a no ser que sean organizaciones envueltas en actividades ilícitas. En el siguiente apartado explicamos estas conclusiones.

\section{Metodología estadística para el análisis de resultados.}

Se aplicaron cuestionarios a personas que forman parte de la población económicamente activa en México, como un módulo especial del trabajo aplicado junto con la encuesta nacional de hogares en 2014.

La escala de medición utilizada para identificar las respuestas de los cuestionarios aplicados por INEGI (2014) se reduce al intervalo entre 0 y 1. Por esta razón resulta inadecuado utilizar los métodos estadísticos paramétricos tradicionales que en buena medida hacen uso del supuesto de normalidad sobre los datos manejados.

El análisis estadístico realizado en esta investigación, de acuerdo con sus objetivos, se basa fundamentalmente en métodos estadísticos no paramétricos, en el sentido de que estos procedimientos se asumen como libres de algún supuesto distribucional.

La finalidad de utilizar métodos estadísticos no paramétricos en esta investigación fue realizar un contraste de la significancia entre los resultados promedio de responsabilidad entre la empresa y los trabajadores. En reiteradas ocasiones fue necesario probar si existían diferencias significativas entre los diferentes tipos de responsabilidad de la empresa y los diferentes tipos de responsabilidad de los trabajadores.

De esta manera en este trabajo se empleó la prueba estadística no paramétrica de Kruskall y Wallis. Dicha prueba se describe en seguida.

\subsection{Prueba de Kruskal y Wallis.}

Esta prueba no paramétrica se basa únicamente en los rangos de las observaciones y permite probar la hipótesis de si un conjunto de poblaciones son idénticas. La prueba puede ser planteada de la siguiente manera. Sean $\mathrm{X}_{11}, \mathrm{X}_{12}, \ldots, \mathrm{X}_{1 \mathrm{n} 1} ; \mathrm{X}_{21}, \mathrm{X}_{22}, \ldots, \mathrm{X}_{2 \mathrm{n} 2} ; \ldots ; \mathrm{X}_{\mathrm{q} 1}, \mathrm{X}_{\mathrm{q} 2}, \ldots, \mathrm{X}_{\mathrm{qnq}}, \mathrm{q}$ muestras aleatorias de tamaño ni, $\mathrm{i}=1,2, \ldots, \mathrm{q}$ con funciones de distribución desconocidas. Estamos 
interesados en probar la hipótesis nula (Villaseñor y Díaz, 2003):

$\mathrm{H} 0: \mathrm{F}_{1}(\mathrm{x})=\mathrm{F}_{2}(\mathrm{x})=\ldots=\mathrm{Fq}_{\mathrm{q}}(\mathrm{x})=\mathrm{F}(\mathrm{x})$

contra la hipótesis alternativa:

$\mathrm{H} 1: \mathrm{Fi}(\mathrm{x})=\mathrm{F}(\mathrm{x}-\theta i) \quad($ para toda $x, i=1,2, \ldots, q)$

con las $\theta i$ 's no todas iguales (Kruskal, 1952).

La prueba se obtiene primero ordenando los $N=\sum_{i=1}^{q} n_{i}$ valores de menor a mayor y asignando

los rangos correspondientes a las $N$ observaciones. Utilicemos $R$ ij para denotar el j-ésimo rango en la i-ésima muestra $(i=1,2, \ldots, q ; j=1,2, \ldots, n i)$.

Ahora, sea $R \mathrm{i}=\sum_{j=1}^{n i} R_{i j}$ la suma de los rangos de todos los ni valores de la i-ésima muestra y sea $\quad R_{i}=\frac{R_{i}}{n_{i}}$, por lo que $\sum_{i=1}^{q} R_{i}=\frac{N(N+1)}{2}$.

Bajo la hipótesis nula, los ni rangos de la i-ésima muestra fueron seleccionados aleatoriamente del conjunto $\{1,2, \ldots, \mathrm{N}\}$. Por lo que éstos constituyen una muestra aleatoria de tamaño ni extraída sin remplazo de una población finita de $\mathrm{N}$ enteros. De esta manera, los ni rangos en la i-ésima muestra tienen distribución uniforme discreta (Larios, 1999):

Como $R$ i es una media muestral, si ni $\square 5$ (Montgomery, 1997), por el teorema central del límite (TCL) es posible aproximar la distribución de

$$
\mathrm{Z}_{\mathrm{i}}=\frac{\bar{R}_{i}-(N+1) / 2}{\sqrt{(N+1)\left(N-n_{i}\right) / 12 n_{i}}}
$$

con media:

$$
\mathrm{E}\left[\bar{R}_{i}\right]=E\left[\frac{1}{n_{i}} \sum_{j=1}^{n_{i}} R_{i j}\right]=\frac{n_{i}}{n_{i}} \frac{(N+1)}{2}=\frac{N+1}{2}
$$

y varianza:

$$
\operatorname{Var}\left[\bar{R}_{i}\right]=\frac{1}{\left(n_{i}\right)^{2}}\left[\frac{n_{i}\left[N^{2}-1\right]}{12}+n_{i}\left(n_{i}-1\right)\left[-\frac{N+1}{12}\right]\right]=\frac{[N+1]\left[N-n_{i}\right]}{12 n_{i}}
$$


por la distribución normal estándar. Consecuentemente $\mathrm{Zi}^{2}$ se distribuirá aproximadamente como una Chi-cuadrada con un grado de libertad. Esto se mantiene para $i=1,2, \ldots, q$; sin embargo, se observa que las variables aleatorias $\mathrm{Zi}$ no son independientes pues $\sum_{i=1}^{q} n_{i} \bar{R}_{i}=\frac{N(N+1)}{12}$ es una constante (Gibbons, 1985), lo cual limita aproximar la distribución de $\sum_{i=1}^{q} Z_{i}^{2}$ por una Chi-cuadrada con q grados de libertad. Sin embargo, considerando un factor de corrección dado por (N-ni)/N (Kruskal, 1952), se puede mostrar bajo la hipótesis nula que $\mathrm{H}=\sum_{i=1}^{q} \frac{N-n_{i}}{N} Z_{i}^{2}$ se distribuye asintóticamente como una variable aleatoria chi-cuadrada con (q-1) grados de libertad. Sustituyendo el valor de (Bradley, 1968) se observa que:

$$
\mathrm{H}=\frac{12}{N(N+1)}\left[\sum_{i=1}^{q} \frac{R_{i}^{2}}{n_{i}}-N\left(\frac{N+1}{2}\right)^{2}\right]=\frac{12}{N(N+1)} \sum_{i=1}^{q} \frac{R_{i}^{2}}{n_{i}}-3(N+1)
$$

donde $\mathrm{H}$ se distribuye aproximadamente como chi-cuadrada con $q-1$ grados de libertad. Puesto que valores pequeños de $\mathrm{H}$ apoyan la hipótesis nula y se rechaza cuando $\mathrm{H}$ es suficientemente grande, la regla de decisión es rechazar $\mathrm{H} 0$ cuando $\mathrm{H}>\chi^{2} \alpha, \mathrm{q}-1$.

\section{Resultados: responsabilidad y pobreza en México.}

Arim y De Melo (2014:181) sostienen que, desde la perspectiva de políticas públicas, una aproximación que resulta más consistente con el enfoque de capabilidades es la implementación de medidas de combate a la pobreza que permitan identificar, dentro de una sociedad, a los individuos que son incapaces de generar por sí mismos el flujo de recursos imprescindibles para alcanzar una vida decorosa.

La incapacidad de generar un nivel de ingresos mínimo, así como la falta de agencia, pueden reflejarse en una debilidad y vulnerabilidad mayor que la carencia de ingresos. Así, pasamos a concentrarnos en los estudios de pobreza de la disponibilidad efectiva de medios a la capacidad para generar autónomamente esos medios.

La presencia de la calidad de agencia en un individuo, nos permitiría ver cuáles son las personas que tienen esta capacidad, no solo de generar ingreso sino de convertir los bienes primarios, las capabilities, en bienestar. Vamos a ver en qué situación se encuentra México.

Primero, vamos a ver los resultados agregados y después por entidad federativa. Esto nos permitirá evaluar cuáles son los estados que se encuentran en una situación más favorable en términos de agencia lo que permitiría a la población económicamente activa mejorar su bienestar. Para ello vamos a retomar los datos publicados en nuestro artículo de 2017 basados en el módulo especial del trabajo de la encuesta nacional de hogares del INEGI de 2014. 
Lo que hemos encontrado es que el nivel de responsabilidad en sus tres categorías es heterogéneo y que sobre todo existe un bajo nivel de responsabilidad autrui de la empresa y un bajo nivel de responsabilidad posterior del trabajador.

En la tabla 1, vemos que a nivel agregado la calidad de agencia no se alcanza, ya que dos categorías de responsabilidad no están presentes, la responsabilidad de autrui de la empresa y la responsabilidad posterior del trabajador.

De estos primeros resultados agregados se ve que la empresa valora la responsabilidad posterior y la responsabilidad anterior mientras que es de poca importancia la responsabilidad hacia los demás, es decir poco importan los efectos de los actos hacia los otros (o las externalidades).

Herrera, Nebel y Carreño (2017), mencionan que los trabajadores al contrario de la firma valoran Responsabilidad autrui (RUT) a niveles muy elevados, así como la Responsabilidad anterior (RAT), pero visiblemente temen o no aprecian Responsabilidad posterior (RPT). Esto nos habla del rol arquitectónico de la responsabilidad autrui en la construcción de la responsabilidad humana. Hemos de considerar aquí lo que significa estos datos: a pesar de tener una responsabilidad autrui de la empresa (RUF) de 39\%, los trabajadores valoran y actúan sobre la base de una RUT de 93\% (Overshooting 54\% del nivel esperado). El nivel increíblemente elevado es alcanzado a pesar de la firma, en contra podríamos decir de lo que espera la firma de sus trabajadores. No es aquí solo un acto de resistencia hacia la organización del trabajo en la firma, pero la afirmación que la responsabilidad que no valora la firma es de suma importancia para el trabajador, más que todo los otros tipos de responsabilidades.

Tabla 1

\section{Responsabilidad}

\begin{tabular}{|l|l|l|l|l|l|}
\hline $\begin{array}{l}\text { Responsabilidad Firma } \\
\text { (RF) }\end{array}$ & Promedio & Des.S & $\begin{array}{l}\text { Responsabilidad } \\
\text { trabajadores (RT) }\end{array}$ & Promedio & Des.S. \\
\hline $\begin{array}{l}\text { Responsabilidad Posterior } \\
\text { (Real) (RPF) }\end{array}$ & 0.83 & 0.27 & $\begin{array}{l}\text { Responsabilidad Posterior } \\
\text { (Real) (RPT) }\end{array}$ & 0.49 & 0.45 \\
\hline $\begin{array}{l}\text { Responsabilidad Anterior } \\
\text { (Real) (RAF) }\end{array}$ & 0.76 & 0.36 & $\begin{array}{l}\text { Responsabilidad Anterior } \\
\text { (Real) (RAT) }\end{array}$ & 0.80 & 0.34 \\
\hline $\begin{array}{l}\text { Responsabilidad Autrui } \\
\text { (Real) (RUF) }\end{array}$ & 0.35 & 0.38 & $\begin{array}{l}\text { Responsabilidad Autrui (Real) } \\
\text { (RUT) }\end{array}$ & 0.93 & 0.20 \\
\hline Total Real Responsabilidad. & 0.65 & & Total Real Responsabilidad & 0.74 & \\
\hline
\end{tabular}

Nota: Se realizó una prueba de hipótesis de Kruskal-Wallis para cada combinación (par) de los distintos tipos de "Responsabilidad" entre empresa y trabajador. De esta manera se realizaron nueve contrastes en total considerando niveles de significancia de 0.05 y 0.10. En todos los casos se rechazó la hipótesis nula de homogeneidad de poblaciones, excepto donde se contrastó Responsabilidad Posterior del Trabajador contra Responsabilidad Autrui del Trabajador. Por lo que en este último caso se entiende que las poblaciones, así como sus medias, son equivalentes. En el resto de las combinaciones se encontró que las poblaciones y promedios de las responsabilidades presentan diferencias significativas, lo que muestra una gran heterogeneidad (no convergencia) en cuanto a los diferentes tipos de responsabilidad entre la misma empresa, los mismos trabajadores y en la combinación entre ambos agentes. Fuente: cálculos del autor, basados en el módulo especial del trabajo de la encuesta nacional de hogares del INEGI de 2014. 
Los trabajadores valoran RUT, pero evaden visiblemente Responsabilidad posterior (49\%). Cabe recordar que una cifra debajo del 50\% tiene que ser considerada como no sostenible y económicamente desastrosa. Quizás sea esto el dato económico más preocupante de la encuesta. Si a nivel de la República Mexicana, en el contexto laboral, los trabajadores solo admiten ser los autores de un acto que cometieron en el $49 \%$ de los casos, la ineficiencia productiva que esto genera es enorme. Una organización (gobierno, escuelas, empresas, etc.) en México, tiene que asumir que en la mitad de los casos los empleados (aquí son empleados a todos los niveles, gerentes, secretarias, contadores, obreros, etc) no van a hacerse responsables de sus actos, es más, van a evadir sus responsabilidades de manera activa, sea escondiendo el hecho, negándolo o inventando pretextos.

Como ya lo decimos en 2017 (Herrera, Nebel y Díaz, 2017), este bajo nivel de responsabilidad posterior no resulta ser una incapacidad de los trabajadores sino más bien una forma de evasión de la responsabilidad, probablemente ligada a la implementación de la responsabilidad posterior. La responsabilidad hacia nuestros actos (RPT) deriva efectivamente antropológicamente de la capacidad que tenemos de hacernos responsables de algo (RAT). El nivel alto de RAT de los trabajadores $(80 \%)$ implica por lo tanto que no se trata aquí de una incapacidad, sino más bien de una valoración negativa de la responsabilidad posterior del trabajador. No se aprecia el hecho de hacerse responsable de sus actos en el ámbito laboral. ¿Por qué? Quizás por una implementación sobre todo negativa de RPF por parte de la empresa, es decir una implementación como sanción de fallos/errores, y no de manera positiva por medio de un reconocimiento de lo que se hizo bien o como apreciación de la toma de responsabilidad (incluso en el caso de errores asumidos).

Finalmente es importante ser atento que la desviación estándar de la RPT es de 45\%. Existen por lo tanto resultados individuales muy diferentes al respecto de la RPT. Veremos más abajo el estudio de la dispersión de los resultados. Sin embargo, adelantando aquí esta discusión, parece que esta alta desviación estándar refleja la diversidad en términos de cualificación educativa de los puestos en la organización laboral. Mientas más elevado sea el nivel educativo, más elevado será el score de RPT por trabajador. Inversamente, también significa que, entre los trabajadores con poca educación, los niveles de RPT estarán todavía dramáticamente más bajos (ver Herrera, Nebel y Díaz, 2017).

\subsection{Resultados por entidad federativa.}

En la tabla 2 tenemos resultados por entidad federativa y hemos considerado las entidades con mayor ingreso por un lado y por el otro las entidades con menor ingreso según la clasificación de INEGI. Vemos en estos datos que los niveles de responsabilidad guardan las mismas características que se muestran a nivel agregado y no hemos encontrado diferencias por grupos de estados.

Esto es importante en materia de pobreza, ya que en ambos estados hay pobres y el hecho 
que el nivel de responsabilidad autrui de la empresa sea muy bajo, actúa como un ancla que contamina y genera más pobreza, como lo enunciamos más arriba esto no permite que los individuos puedan convertir los bienes primarios en bien estar, impidiéndoles salir de su situación de pobreza. Lo que podemos decir además es que este efecto es mayor en los estados más pobres ya que estos tienen mayores carencias.

Un ejemplo de lo anterior sería el caso de empresas públicas o privadas de servicios o de bienes que contaminan y que están ocasionando, por ejemplo, una carencia en las personas, como daños a la salud. Los efectos negativos de esta externalidad en personas con carencias de ingresos, es más fuerte ya que no les es posible pagar los servicios necesarios para atenderse, ya sea por falta de seguro social, o por la lejanía de hospitales o centros de salud. Mientras que en personas con mayor ingreso estos tienen la posibilidad de remediar esta carencia o de encontrar otras soluciones.

Por otro lado, la responsabilidad posterior tan baja de los trabajadores impide un buen funcionamiento eficiente de la empresa pública o privada y esto puede generar altos costos, ya que estas personas no son capaces de cumplir con las metas o las obligaciones que dicen tener o planear ya que nunca las realizan. Esto en una empresa tanto privada como pública implica estar controlando, auditando constantemente el trabajo de los empleados. Pero como decíamos más arriba es posible que esta baja responsabilidad posterior sea debida a la manera como la empresa en México implementa éste tipo de responsabilidad y que en otros ámbitos como el familiar sea más alto.

También vemos en esta segunda tabla, que dentro de los estados pobres y ricos existen estados particularmente preocupantes, porque carecen de responsabilidad en tres categorías, estos son: el Distrito Federal, Nuevo León, Guerrero, Puebla y Veracruz, en otras palabras. Pero Guerrero y Puebla son los estados donde la población económicamente activa está en peores condiciones. El caso de Veracruz es también preocupante, pues refleja no tener responsabilidad en 4 categorías de responsabilidad.

En Chihuahua, lo que vemos es que no tienen responsabilidad posterior del trabajador, pero su nivel es superior al promedio de toda la República Mexicana, mientras que la responsabilidad autrui de la empresa con un .31 está por abajo del promedio del país (.35). Cómo decíamos más arriba, también en este estado la baja responsabilidad de la empresa actúa como un ancla y no permite mejorar las condiciones laborales de los trabajadores. 
Tabla 2

Responsabilidad: estados urbanos y ricos versus estados pobres y rurales

\begin{tabular}{|c|c|c|c|c|c|c|}
\hline $\begin{array}{l}\text { Estados urbanos y ricos } \\
\text { Nivel educativo alto; ingreso } \\
\text { elevado; pobreza < <30\%; } \\
\text { extrema pobreza }<10 \% \text {; sobre } \\
\text { todo industria y servicios. }\end{array}$ & $\begin{array}{l}\text { Resp. } \\
\text { Posterior } \\
\text { de la } \\
\text { Empresa }\end{array}$ & $\begin{array}{l}\text { Resp. } \\
\text { Posterior } \\
\text { del } \\
\text { Trabaja- } \\
\text { dor }\end{array}$ & $\begin{array}{l}\text { Resp. } \\
\text { Anterior } \\
\text { de la } \\
\text { Empresa }\end{array}$ & $\begin{array}{l}\text { Resp. } \\
\text { Anterior } \\
\text { del } \\
\text { Trabajador }\end{array}$ & $\begin{array}{l}\text { Resp. } \\
\text { Autrui } \\
\text { de la } \\
\text { Empresa }\end{array}$ & $\begin{array}{l}\text { Resp. } \\
\text { Autrui } \\
\text { del } \\
\text { Traba- } \\
\text { jador }\end{array}$ \\
\hline Distrito Federal & 0.85 & 0.55 & 0.70 & 0.85 & 0.34 & 0.91 \\
\hline Nuevo León & 0.81 & 0.61 & 0.73 & 0.76 & 0.30 & 0.94 \\
\hline Sonora & 0.87 & 0.56 & 0.83 & 0.79 & 0.35 & 0.92 \\
\hline Baja California Sur & 0.85 & 0.42 & 0.81 & 0.74 & 0.32 & 0.94 \\
\hline Chihuahua & 0.83 & 0.51 & 0.79 & 0.84 & 0.31 & 0.93 \\
\hline \multicolumn{7}{|l|}{$\begin{array}{l}\text { Estados rurales y pobres } \\
\text { Nivel de educación bajo; } \\
\text { pobreza > 75\%; extrema } \\
\text { pobreza }>24 \% \text {; sector informal } \\
>72 \% \text {; agricultura }>30 \%\end{array}$} \\
\hline Chiapas & 0.75 & 0.35 & 0.76 & 0.86 & 0.24 & 0.92 \\
\hline Oaxaca & 0.87 & 0.47 & 0.75 & 0.80 & 0.51 & 0.94 \\
\hline Guerrero & 0.88 & 0.36 & 0.67 & 0.80 & 0.29 & 0.97 \\
\hline Puebla & 0.83 & 0.42 & 0.73 & 0.77 & 0.35 & 0.86 \\
\hline Veracruz & 0.74 & 0.42 & 0.73 & 0.84 & 0.43 & 0,92 \\
\hline
\end{tabular}

Nota: Comparando de manera agregada Estados Ricos vs Estados Pobres no se tienen diferencias significativas en los diferentes tipos de responsabilidad, esto de acuerdo con la prueba de Kruskal y Wallis al 5\% de significancia. Lo que significa que la ausencia de responsabilidad posterior del trabajador y responsabilidad autrui de la firma en el grupo de estados ricos, es la misma problemática que se encuentra en el grupo de estados pobres. No obstante, al interior de los grupos de estados ricos y pobres si existen diferencias significativas entre los diferentes tipos de responsabilidad entre las mismas empresas, mismos trabajadores y en la combinación de ambos.

Fuente: cálculos del autor, basados en el módulo especial del trabajo de la Encuesta Nacional de Hogares del INEGI de 2014.

\subsection{Responsabilidad y extrema pobreza en la PEA.}

En esta parte queremos ver cuál es el nivel de responsabilidad en los individuos que forman parte de la población económicamente activa y que están en situaciones de extrema pobreza. Las variables que seleccionamos como indicadores de extrema pobreza son los que pudimos encontrar en la Encuesta Nacional de Hogares: si las personas duermen en la cocina; número de cuartos por hogar; no tienen acceso al agua corriente; datos de alfabetización (leer y escribir); son divorciados; no pueden caminar.

Lo que podemos ver en la tabla 3, es que los individuos más pobres de la sociedad no es que no sean responsables, de hecho, tienen niveles altos de responsabilidad anterior y de responsabilidad autrui incluso por arriba del promedio nacional.

Estos resultados permiten afirmar una primera cosa: a) La pobreza no está correlacionada con bajos niveles de capabilidad de agencia. Quien sea pobre no presenta carencia de capabilidad 
de agencia en su ámbito laboral. El pobre valora y actúa incluso con mayor responsabilidad para otros y hacia sí-mismo, sus resultados están por arriba de la media nacional. La pobreza no es causa de una carencia de capabilidad de agencia del trabajador.

Tabla 3

Nivel de responsabilidad (resp.) de la PEA más pobres a nivel de toda la República Mexicana

\begin{tabular}{|l|c|c|c|c|}
\hline & $\begin{array}{l}\text { Resp. Posterior } \\
\text { del trabajador }\end{array}$ & $\begin{array}{l}\text { Resp. } \\
\text { Anterior del } \\
\text { trabajador }\end{array}$ & $\begin{array}{l}\text { Resp. } \\
\text { Autrui del } \\
\text { trabajador }\end{array}$ & $\begin{array}{l}\text { Resp. } \\
\text { Autrui } \\
\text { de } \\
\text { empresa } \\
\text { la }\end{array}$ \\
\hline No tienen acceso al agua corriente & 0.58 & 0.90 & 0.97 & 0.34 \\
\hline No saben leer / escribir & 0.33 & 0.95 & 0.97 & 0.37 \\
\hline Duermen en la cocina & 0.47 & 0.91 & 0.98 & 0.32 \\
\hline $\begin{array}{l}\text { No tienen acceso al agua y están } \\
\text { divorciados }\end{array}$ & 0.52 & 0.79 & 0.93 & 0.32 \\
\hline $\begin{array}{l}\text { Viven en menos de .25 cuartos por } \\
\text { persona }\end{array}$ & 0.28 & 0.87 & 0.93 & 0.30 \\
\hline $\begin{array}{l}\text { No acceso al agua corriente, viven } \\
\text { en menos de .25 cuartos por } \\
\text { persona y tienen dificultad para } \\
\text { caminar }\end{array}$ & 0.28 & 0.87 & 0.93 & 0.32 \\
\hline
\end{tabular}

Fuente : Cálculos del autor en base a la Encuesta Nacional de Hogares, 2014, de INEGI.

Es decir, que estas personas son capaces de convertir los instrumentos (dados o no por la sociedad) en logros y pueden elegir libremente la vida que desea vivir. Si los trabajadores en situaciones de extrema pobreza son responsables, sólo nos queda que es su contexto laboral el que no les permite salir de sus condiciones de pobreza material. Si comparamos la tabla 3 y 4 , vemos que tanto los individuos en extrema pobreza como los individuos con menos carencias dicen que a las empresas no les interesan sus efectos hacia los demás. Pero, lo que vemos es que el nivel de responsabilidad autrui de la empresa es más bajo en la PEA con más carencias que el nivel de responsabilidad de la empresa de la PEA con menos carencias. Así pues, los efectos negativos de una falta de responsabilidad autrui de la empresa son más importante sobre la PEA con mayores carencias.

En el Anexo 1, encontraremos los resultados por entidad federativa, en ellos se verá cuáles son los niveles de responsabilidad en las tres categorías en cada una de ellas. 
Tabla 4

Nivel de responsabilidad de la PEA con menos carencias

\begin{tabular}{|l|l|l|l|l|}
\hline & $\begin{array}{l}\text { Resp. } \\
\text { Posterior del } \\
\text { trabajador }\end{array}$ & $\begin{array}{l}\text { Resp. } \\
\text { Anterior del } \\
\text { trabajador }\end{array}$ & $\begin{array}{l}\text { Resp. } \\
\text { Autrui del } \\
\text { trabajador }\end{array}$ & $\begin{array}{l}\text { Resp. } \\
\text { Autrui de la } \\
\text { empresa }\end{array}$ \\
\hline $\begin{array}{l}\text { Tienen acceso al agua corriente dos } \\
\text { veces por semana }\end{array}$ & 0.65 & 0.80 & 0.93 & 0.41 \\
\hline Saben leer y escribir & 0.49 & 0.79 & 0.93 & 0.49 \\
\hline Sanitarios con agua & 0.53 & 0.79 & 0.93 & 0.34 \\
\hline $\begin{array}{l}\text { Tienen más de un cuarto por } \\
\text { persona en sus viviendas }\end{array}$ & 0.58 & 0.80 & 0.93 & 0.33 \\
\hline Están casados & 0.53 & 0.83 & 0.93 & 0.34 \\
\hline $\begin{array}{l}\text { Tienen por arriba de un nivel de } \\
\text { licenciatura y tienen más de un } \\
\text { cuarto por persona. }\end{array}$ & 0.66 & 0.81 & 0.92 & 0.37 \\
\hline
\end{tabular}

Fuente: Cálculos del autor en base a la Encuesta Nacional de Hogares, 2014, de INEGI. 


\section{P. Conclusiones.}

Hemos tratado de dar aquí elementos que pueden explicar los problemas de pobreza que enfrenta la PEA en México. Nos hemos apoyado en el enfoque de capabilidades y en las aportaciones recientes que subrayan la importancia de la agencia para el bienestar, medida a través de la responsabilidad. Así pues, encontramos que en México existen todavía grandes retos en términos de la cualidad de la agencia. Particularmente creemos que los rezagos en materia de pobreza, son debidos a la falta de responsabilidad posterior y responsabilidad autrui o hacia los demás de la empresa. Más arriba decíamos que hay que preocuparse por elevar los niveles de responsabilidad anterior, autrui de las empresas públicas y privadas, y la responsabilidad posterior de los trabajadores. Pero esta última no a través de ignorar los trabajadores y castigar directamente los errores, sino de escuchar sus propuestas y opiniones

Consideramos que la cualidad de la agencia es una condición de base que tiene que estar dada en una sociedad, sin ella la disminución de la pobreza seguirá rezagada en éste sector. Los trabajadores tienen derecho a mejorar su nivel de bienestar. Cómo bien se apreciará éste es un problema de fondo y la solución llegará en el largo plazo. Este es un llamado hacer una reflexión inmediata sobre nuevas políticas de empleo. Un aumento de los salarios es importante pero no suficiente, una mejora de los niveles de responsabilidad tanto de la empresa como del trabajador, si nos asegura un aumento en el bienestar de este sector de la población.

Estos elementos arriba citados también nos invitan a pensar en diseñar una política industrial que éste guiada por criterios de elección de progreso técnicos que consideren tanto variables económicas como humanas. La elaboración de éstos criterios y su aplicación en política industrial son de vital importancia para México. Una proposición de criterios de elección reciente se puede ver en Herrera R. N. María Teresa (2016). 


\section{Bibliografía y referencias documentales}

Arim Rodrigo y De Melo Gioia (2014). "Un análisis multidimensional de la pobreza en Uruguay, 19912005”, en Nebel, M., Flores-Crespo, P., H.R. Nebel, M.T. (Ed.) (2014). Desarrollo como libertad en América Latina. Fundamentos y Aplicaciones, México: Editorial Universidad Iberoamericana, 223-244 pp.

Ballet Jerôme., Bazin Damien., Dubois Jean Louis, Mahieu Francois Régis., (2014). Freedom, Responsibility and Economics of the Person, London, Routledge.

Bertin, Alexandre (2014), "Glosario de los términos utilizados en el enfoque de capabilities", en Nebel, M., Flores-Crespo, P., H.R. Nebel, M.T. (Ed.) (2014). Desarrollo como libertad en América Latina. Fundamentos y Aplicaciones, México: Editorial Universidad Iberoamericana, 442p.

Bovens, Mark, (1998). The Questfor Responsibility, Accountability and Citizenship in Complex Organizations, Cambridge, CUP.

Bradley, James (1968). Distribution-Free Statistical Test. Prentice Hall, Englewood Cliffs, NJ.

CEPAL (2011), Sistema de protección social en México a inicios del siglo XXI, ed. Naciones Unidas, Chile.

Cortina, Adela (2007). Ética de la razón cordial: educar en la ciudadanía en el siglo XXI. Oviedo: Nobel.

Crocker, David (2009). Ethics of global development. Agency, Capability and Deliberative Democracy, Cambridge: Cambridge University Press.

Gibbons, Jean (1985). Nonparametric Statistical Inference. 2nd edition. Marcel Dekker, New York, NY.

Herrera R. N. María Teresa, Nebel, Mathias y Díaz C. Miguel (2017). "Medición de la meta-capabilidad de agencia en el ámbito laboral. Agencia, responsabilidad y bienestar en México". Ethique et Economie, Vol. 14, No.2, 26-57 pp.

Jonas, Hans., (1979). Das Prinzip Verantwortung, Frankfurt am Main : Insel Verlag.

Kruskal, William (1952). “A nonparametric Test for the Several Sample Problem”. The Annals of Mathematical Statistics, 23(4), 525-540.

Larios, Luna (1999). Pruebas de hipótesis para comparar poblaciones Poisson: estudio comparativo. Tesis de Maestria, Colegio de Postgraduados. Texcoco, México.

Lévinas, Emmanuel (1974). Autrement qu'être ou au-delà de l'essence, Nijhoff : Lattaye.

(1982). Ethique et infini, Paris, Fayard, 1982.

Nebel, Mathias, Flores-Crespo, Pedro, Herrera R. N., María Teresa (2014). Desarrollo como libertad en América Latina. Fundamentos y Aplicaciones, México: Editorial Universidad Iberoamericana, 442 pp.

Herrera R. N., María Teresa (2016). "Criterios de elección de progresos técnicos: Eficiencia técnica, empleo, capabilidades y responsabilidad en el sector industrial mexicano", En-Claves del Pensamiento, Año X, No. 20, 57-78.

(2017). "Midendo la meta-capabilidad de agencia: base teórica para la creación de un indicador de responsabilidad". Ethique et Economie, Vol. 14, No.2, 3-24 pp.

PNUD (2003, 2004, 2010, 2015). Informe sobre desarrollo humano, ed. Mundi-Prensa, 367 pp.

Ricœur, Paul (1989). Soi-même comme un autre, Paris : Seuil.

Ronill, Jesús (2004). Horizontes de economía ética, Aristóteles, Adam Smith, Amartya Sen, ed, Tecnos, Madrid, $282 \mathrm{pp}$.

Rösner, Hans (2012). Política de empleo y el mercado laboral en el marco de la Economía Social de Mercado, Serie 5, Economía Social de Mercado, ed. Fundación Konrad Adenauer, Guatemala. 
Agencia y pobreza en la población económicamente activa... • María Teresa Herrera Rendón Nebel y Miguel Ángel Díaz Carreño

Robeyns, Ingrid (2004). "Capabilidades y teorías de la justicia social" en Nebel, M., Flores-Crespo, P., Herrera R. Nebel, M.T. (2014). Desarrollo como libertad en América Latina. Fundamentos y Aplicaciones, México: Editorial Universidad Iberoamericana, 73-96 pp.

Sen, Amartya (1985). "Well-being, Agency and Freedom: the Dewey Lectures 1984", Journal of Philosophy $82,169-221 \mathrm{pp}$.

(1992). Inequality Reexamined, Oxford: OUP.

(1999), Development as Freedom, Knopf Press, New York.

Villaseñor-Alva, José y Díaz Miguel (2003). Pruebas no paramétricas para procesos Poisson no homogéneos, Agrociencia, Volumen 37, número 1, 21-31 pp. 
Anexo 1

Nivel de responsabilidad (Resp.) por entidad federativa

\begin{tabular}{|c|c|c|c|c|c|c|c|c|}
\hline Entidad Federativa & $R P F^{*}$ & $R P T^{*}$ & $R A F^{*}$ & $R A T^{*}$ & $R U F^{*}$ & $R U T^{*}$ & $\begin{array}{c}\text { Resp. } \\
\text { Total } \\
\text { empresa }\end{array}$ & $\begin{array}{c}\text { Resp. } \\
\text { Total } \\
\text { trabajador }\end{array}$ \\
\hline Aguascalientes & 0,84 & 0,55 & 0,67 & 0,82 & 0,29 & 0,93 & 0,60 & 0,77 \\
\hline Baja California & 0,81 & 0,49 & 0,85 & 0,75 & 0,35 & 0,96 & 0,67 & 0,74 \\
\hline Baja California Sur & 0,85 & 0,43 & 0,81 & 0,74 & 0,33 & 0,94 & 0,66 & 0,70 \\
\hline Campeche & 0,85 & 0,41 & 0,72 & 0,80 & 0,33 & 0,94 & 0,64 & 0,72 \\
\hline Coahuila de Zaragoza & 0,86 & 0,47 & 0,79 & 0,88 & 0,34 & 0,95 & 0,67 & 0,77 \\
\hline Colima & 0,79 & 0,50 & 0,81 & 0,85 & 0,26 & 0,94 & 0,62 & 0,76 \\
\hline Chiapas & 0,76 & 0,35 & 0,76 & 0,87 & 0,25 & 0,93 & 0,59 & 0,72 \\
\hline Chihuahua & 0,83 & 0,51 & 0,79 & 0,84 & 0,31 & 0,93 & 0,64 & 0,76 \\
\hline Distrito Federal & 0,86 & 0,55 & 0,70 & 0,85 & 0,35 & 0,92 & 0,63 & 0,77 \\
\hline Durango & 0,81 & 0,53 & 0,79 & 0,80 & 0,36 & 0,95 & 0,66 & 0,76 \\
\hline Guanajuato & 0,88 & 0,55 & 0,80 & 0,80 & 0,44 & 0,92 & 0,70 & 0,76 \\
\hline Guerrero & 0,89 & 0,37 & 0,67 & 0,81 & 0,30 & 0,98 & 0,62 & 0,72 \\
\hline Hidalgo & 0,81 & 0,65 & 0,72 & 0,75 & 0,43 & 0,94 & 0,65 & 0,78 \\
\hline Jalisco & 0,76 & 0,49 & 0,71 & 0,71 & 0,36 & 0,92 & 0,61 & 0,71 \\
\hline México & 0,90 & 0,62 & 0,74 & 0,83 & 0,34 & 0,91 & 0,66 & 0,79 \\
\hline Michoacán & 0,83 & 0,38 & 0,77 & 0,84 & 0,46 & 0,89 & 0,69 & 0,70 \\
\hline Morelos & 0,84 & 0,48 & 0,78 & 0,75 & 0,37 & 0,90 & 0,66 & 0,71 \\
\hline Nayarit & 0,82 & 0,48 & 0,86 & 0,83 & 0,39 & 0,96 & 0,69 & 0,76 \\
\hline Nuevo León & 0,82 & 0,62 & 0,74 & 0,76 & 0,31 & 0,94 & 0,62 & 0,78 \\
\hline Oaxaca & 0,88 & 0,47 & 0,76 & 0,80 & 0,51 & 0,95 & 0,72 & 0,74 \\
\hline Puebla & 0,83 & 0,42 & 0,73 & 0,77 & 0,35 & 0,86 & 0,63 & 0,68 \\
\hline Querétaro & 0,88 & 0,47 & 0,75 & 0,85 & 0,22 & 0,94 & 0,62 & 0,75 \\
\hline Quintana Roo & 0,89 & 0,46 & 0,75 & 0,79 & 0,34 & 0,97 & 0,66 & 0,74 \\
\hline San Luis Potosí & 0,83 & 0,52 & 0,76 & 0,75 & 0,38 & 0,94 & 0,65 & 0,74 \\
\hline Sinaloa & 0,84 & 0,52 & 0,79 & 0,79 & 0,39 & 0,89 & 0,67 & 0,73 \\
\hline Sonora & 0,87 & 0,55 & 0,84 & 0,80 & 0,40 & 0,92 & 0,70 & 0,76 \\
\hline Tabasco & 0,84 & 0,43 & 0,78 & 0,86 & 0,42 & 0,95 & 0,68 & 0,75 \\
\hline Tamaulipas & 0,84 & 0,40 & 0,75 & 0,82 & 0,21 & 0,97 & 0,60 & 0,73 \\
\hline Tlaxcala & 0,81 & 0,45 & 0,69 & 0,75 & 0,44 & 0,89 & 0,65 & 0,70 \\
\hline Veracruz & 0,74 & 0,42 & 0,73 & 0,84 & 0,43 & 0,92 & 0,64 & 0,73 \\
\hline Yucatán & 0,82 & 0,48 & 0,73 & 0,76 & 0,29 & 0,93 & 0,61 & 0,72 \\
\hline Zacatecas & 0,81 & 0,48 & 0,81 & 0,73 & 0,36 & 0,93 & 0,66 & 0,71 \\
\hline Promedio total & 0,83 & 0,49 & 0,76 & 0,80 & 0,35 & 0,93 & 0,65 & 0,74 \\
\hline
\end{tabular}

Fuente: Cálculos del autor en base a la Encuesta Nacional de Hogares, 2014, de INEGI.

*RPF: Resp. posterior del trabajador ; RPT : Resp. posterior del trabajador; RAF : Resp. anterior del de la empresa; RAT : Resp. anterior del trabajador; RUF : Resp. autrui de la empresa; RUT : Resp. autrui del trabajador. 
Números anteriores:

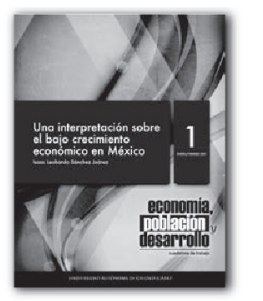

Economía, población y desarrollo.
Cuadernos de trabajo №1

Enero-Febrero 2011
Una interpretación sobre el bajo

crecimiento economico en México
Isaac Leobardo Sánchez Juárez

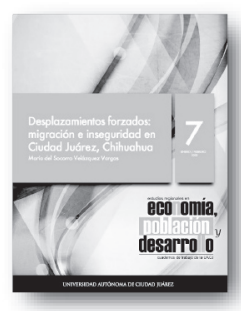

Economia, población y desarroll

Cuadernos de trabajo $\mathrm{N}$ -
Encro-Fcbrcro 2012

Desplazamientos forzados
migración e inseguridad

Ciudad Juárez, Chihuahua
Maria del Socorro Velázquez Varga

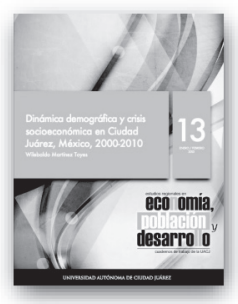

Economiá, población y desarrollo

de trabajo $N$

Dinámica demográ́fica y crisis
socieconómica en Ciudad Juáre Mexico, 2000-2010

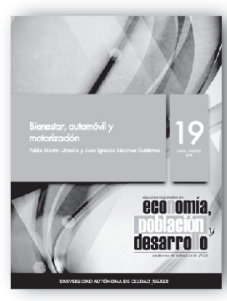

Economía, población y desarroll Enero - Febrero 2014 Bienestar, automóvil y motorización
Pablo Martín Urbano y Miosánchez Gutiérrez

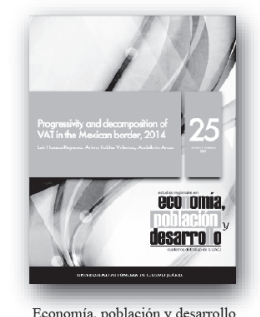

Cuadernos de trabajo No $_{0}$
Conomia,

Encro - Febrero 2015

Progressivity and decomposition of
VAT in the Mexican border, 2014 Abdelkim Araar

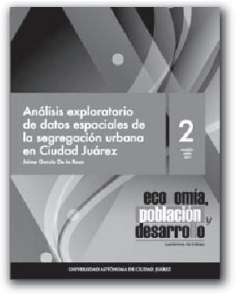

Economía, población y desarrollo.
Cuadernos de trabajo № 2

Marzo-Abril 2011

espaciales de la segregacón

Jaime Garcia De la Rosa

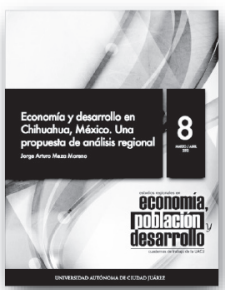

Economia, población y desarrollo

Cuadernos de trabajo №7

Economía y desarrollo en

propuesta de análisis regiona

Jorge Arturo Meza Moreno

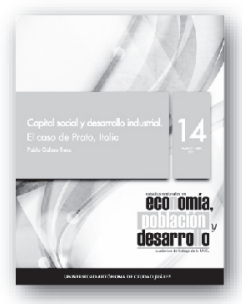

Economía, población y desarrollo

Marzo - Abri1 2013

Capital social y desarrollo

Pablo Galaso Reca

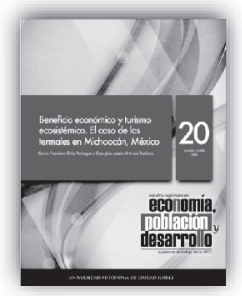

Economia, población y desarrollo

Marzo - Abril 2014

Beneficio económico y turismo

enico. El caso de las ter
en Michoacán, Mésico

arlos Franciseo Ortiz Paniagu

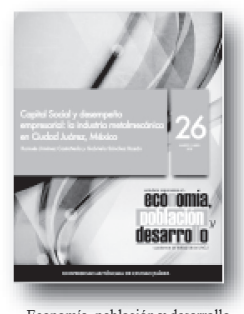

Economía, población y desarrollo

Cuadernos de trabajo № 26
Marzo - Abril 2015

Capital Social y desempeño empresa
la industria metalmecánica en

a industria metalmecánica en
Ciudad Juárez, México

Ramsés Jiménez Castañeda y
Gabriela Sáncez Bazán
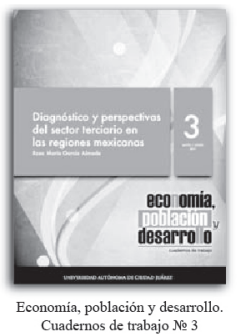

Diagnóstico y perspectivivas

regiones mexicanas
rosa Mária Garcia Almad

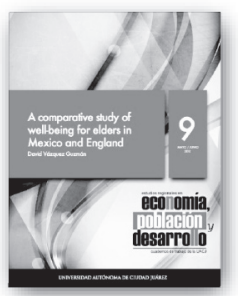

Economia, población y desarrollo

Cuadernos de trabajo № 9
Mayo - Junio 2012

A comparative study of

Mexico and England
David Vázquez Guzmán

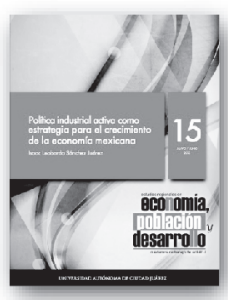

Economia, población y desarroll

Madernos de trabajo
Mayo - Junio 2013

Politica ind ustrial activa como

strategia para el crecimiento

Isaac Lcobardo Ś́nexicana
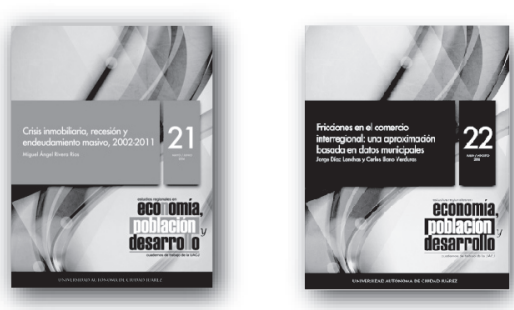

Economia, población y desarrollo

Cuademos de trabajo
Mayo - Junio 2014

Crisis inmobiliaria, recesión y
adeudamiento masivo, $2002-2011$

Miguel Ángel Rivera Rios

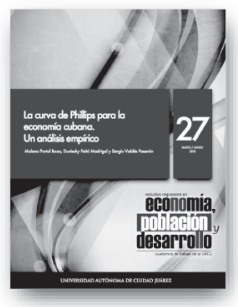

Economia, población y desarrollo

Cuadernos de trabajo № 27

a curva de Phillips para

economía cubana.

Malena Portal Boza, Duniesky Feitó

Economía, población y desarrollo.
Cuadernos de trabsio

julio-Agosto 201

Los indices IDH y FGT en la

mera década del siglo XX

Economía, población y decarrollo

Cuadernos de trabajo №
Julio - Agosto 2012

Political competition and the

edistribution in a federation

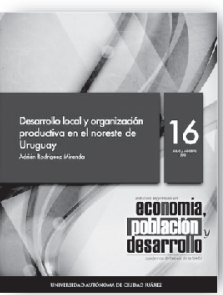

Economía, población y desarrollo

Cuadernos de trabajo №
Julio - Agosto 2013

Desarrollo local y organización
productiva en el noroeste de Urugu

Economía, población y desarrollo

Julio - Agosto 2014

Ficciones en el comercio

basada en datos municipales
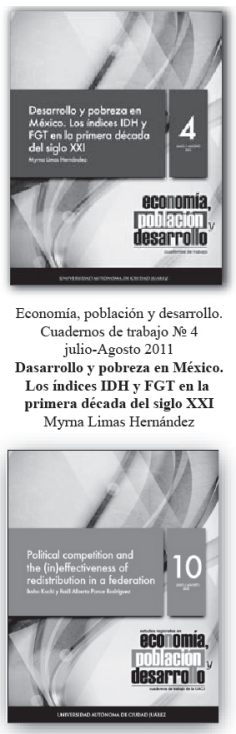

Jorge Diaz Lanchas y Carlos Llano Verduras
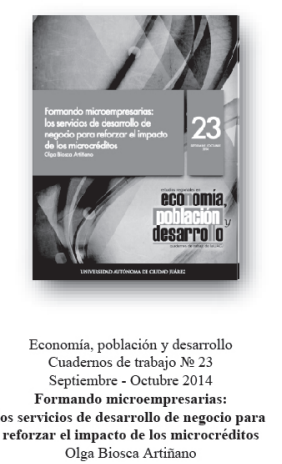

Cuadernos de trabajo № 24

El crecimiento de las regiones

el paradigma del desarrollo

divergente. Un marco térico
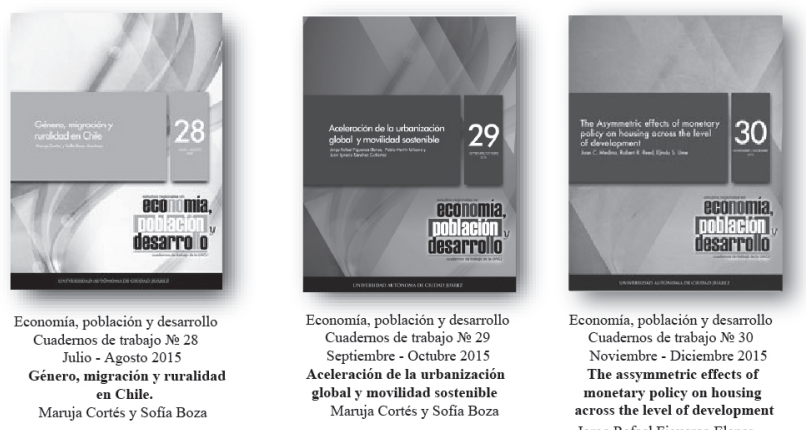

conomía, población y desarrol

Cuadernos de trabajo № 30

The assymmetric effects of

monetary policy on housing

Jorge Rafael Figueroa Elenes,

Juan Ignacio Sánchez Gutiérrez 
Números anteriores:
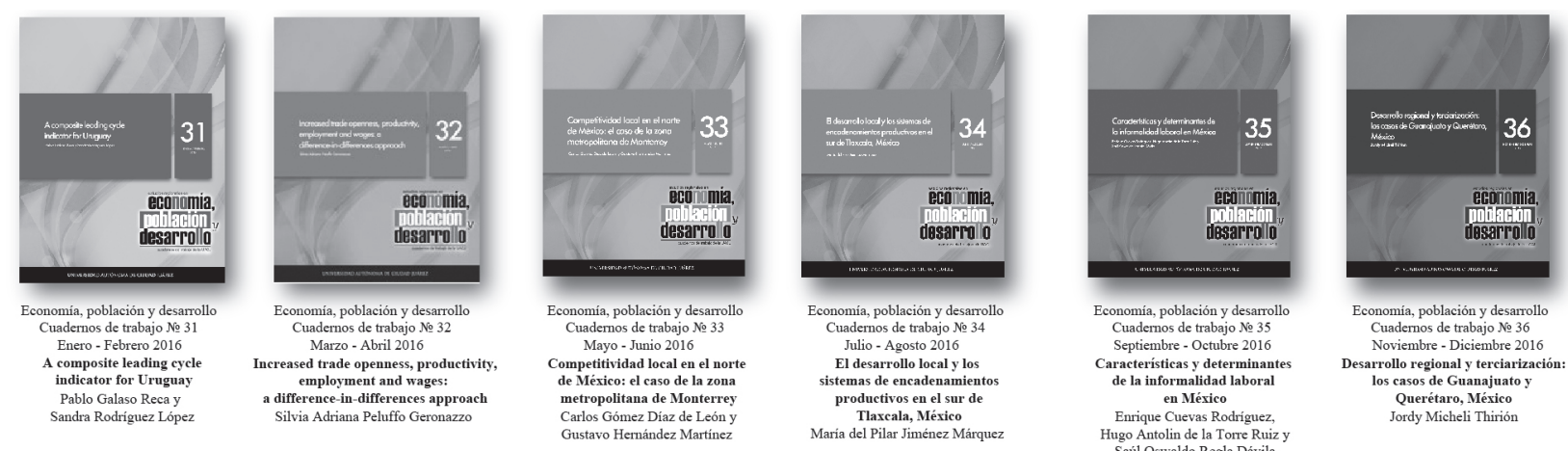

Economía, población y desarrollo Septiembre - Octubre 2016

Caracteristicas $y$ determinantes
de la informalidad laboral en México

Enrique Cucvas Rodrígucz,
Hugo Antolin de lo Torre Ruz

Gustayo Herrández Martinez

Maria del Pilar Jiménez Márquez
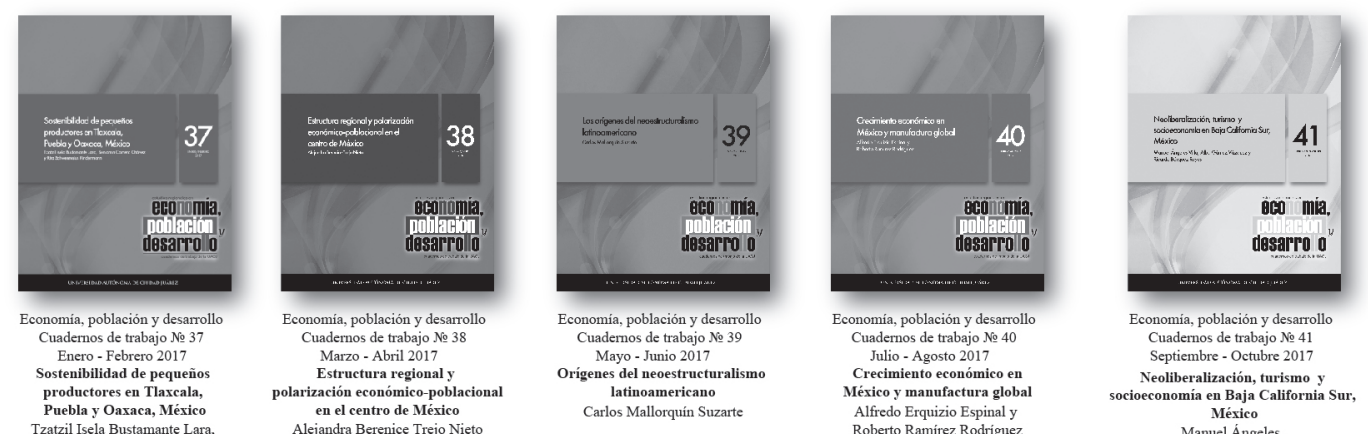

conomia, población y desarroll Noviembre - Diciembre 201

Desarrollo regional y terciarización:
los casos de Guanajuato y

Querétaro, México

Cuadernos de trabajo № 39 Mayo - Junio 2017
Origenes del neoestructuralism latinoamericano

Economia, población y desarrollo Julio - Agosto 2017

Enero - Febrero 201

productores en Tlaxcala,

Izatzil Iscla Bustamante Lara, Benjamin Carrera Chávez y
Rita Schwentesius Rindermann

Alejandra Berenice Trjo Nieto

Carlos Mallorquin Suzarte

ctura global

Alfredo Erquizio Espinal y
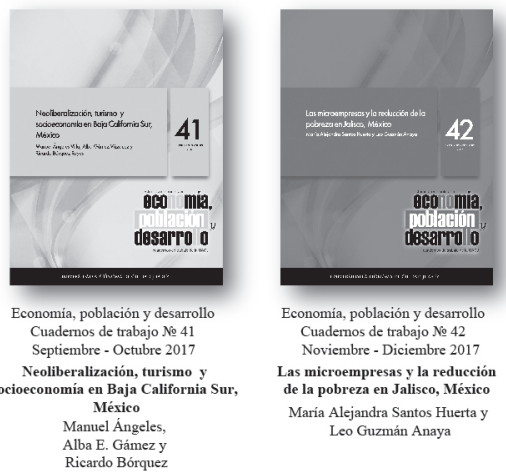
Noviembre - Diciembre 2017 Las microempresas y la reducción
de la pobreza en Jallisco, México Maria Alcjandra Santos Huerta y Leo Guzman Anaya

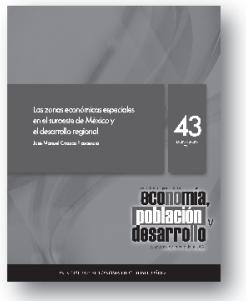

Economia, población y desarrol Cuadernos de trabajo №
Enero - Febrero 2018

Las zonas económicas especiales el desarrollo regional José Manuel Orozco Plascenci

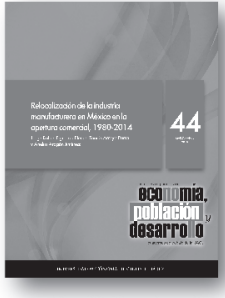

Economia, poblacion y desarrollo Cuadernos de trabajo № 4 Relocalización de la indust

Relocalización de la industria
manufacturera en México en la apertura comercial 1980-2014 Jorge Rafael Figueroa Elenes, Tomás Arroyo Parra y
Aneliss Aragón Jiménez 


\section{$\rightarrow$ Normas Editoriales}

\section{Para el documento general:}

Tipo de letra: Times New Roman.

Tamaño: 11 puntos.

Interlineado: 1.5 espacios.

Títulos y subtítulos:

El texto principal en 11 puntos. Títulos 12 puntos (en resaltado). Subtítulos 11 puntos. Cada título y subtítulo deberá numerarse bajo el siguiente orden: $1,1.1,2,2.1,2.2 \ldots$

La extensión máxima de los cuadernos de trabajo será de 40 cuartillas.

La primera vez que se emplee una sigla en el texto se especificará primero su equivalencia completa y después la sigla.

\section{Hoja de presentación:}

Título:

14 puntos, centrado, resaltado.

Nombre de autor(es):

12 puntos

Resumen y abstract:

Debe incluir resumen en español y abstract (diez puntos), no mayor a 250 palabras

Palabras clave:

Incluir entre tres y cinco palabras clave, en español e inglés

Referencia del autor o autores:

Institución de adscripción, grado académico y líneas-grupos de investigación que desarrolla y a los que pertenece.

\section{Sistema de referencia de citas:}

Harvard-APA

Las citas bibliográficas en el texto deberán incluir entre paréntesis sólo el apellido del autor, la fecha de publicación y el número de página; por ejemplo: (Quilodrán, 2001: 33).

\section{Notación en sección de bibliografía y fuentes de información:}

Se deberá incluir al final del texto. Toda referencia deberá estar mencionada en el texto o notas de pie de página.

Cada referencia iniciará con el primer apellido o los apellidos, luego el nombre del autor, y después, entre paréntesis, el año de publicación seguido de un punto. Ejemplos:

Se deberá incluir al final del texto. Toda referencia deberá estar mencionada en el texto o notas de pie de página.

Cada referencia iniciará con el primer apellido o los apellidos, luego el nombre del autor, y después, entre paréntesis, el año de publicación seguido de un punto. Ejemplos:

Artículo:

Ros, Jaime (2008). "La desaceleración del crecimiento económico en México desde 1982”, en Trimestre Económico, vol. 75, núm. 299, pp. 537-560.

Libro:

Villarreal, René (2005). Industrialización, competitividad y desequilibrio externo en México. 
Un enfoque macroindustrial y financiero (1929-2010), México, Fondo de Cultura Económica. Capítulo de libro:

Castillo, Manuel Ángel (2003). "La política de inmigración en México: un breve recuento", en Manuel Ángel Castillo, Alfredo Lattes y Jorge Santibáñez (coords.), Migración y fronteras, Tijuana, El Colegio de la Frontera Norte / Asociación Latinoamericana de Sociología / El Colegio de México, pp. 425-451.

\section{Notas de pie de página:}

Se utilizarán para hacer indicaciones complementarias, aclaraciones o ampliación de una explicación. La notas de pie de página en Times New Roman, 10 puntos.

\section{Tipología de imágenes dentro del texto:}

Cuadro

Gráfica

Diagrama

Mapa

Figura

Todas las imágenes deben ser numeradas y mencionadas dentro del texto. A toda imagen debe incluirse la fuente.

Las indicaciones de la imagen: tipo y número de imagen, título de imagen y fuente se escriben en 10 puntos. En el texto poner como imagen los mapas, figuras, gráficas y diagramas -con el ánimo de no perder el formato realizado por el autor.

\section{Ecuaciones y fórmulas:}

Si se utilizan ecuaciones o fórmulas deberá utilizarse el editor de ecuaciones de Word y numerarse.

\section{Envío de trabajos}

Los trabajos deben ser enviados a la dirección de correo: lgtz@uacj.mx. Con el Dr. Luis Enrique Gutierrez Casas, editor de esta publicación.

La aceptación de cada colaboración dependerá de la evaluación de dos dictaminadores especialistas en la materia que se conservarán en el anonimato, al igual que el autor (autores) para efectos de la misma. 


\section{$\rightarrow$ Editorial Guidelines}

\section{For General Document:}

Font type: Times New Roman.

Size: font size 11 .

Paragraph: 1.5 line spacing.

Titles and subtitles: Main text font size 11. Titles font size 12 (Bold). Subtitles font size 11.

Each title and subtitle should be numbered in the following order: 1, 1.1, 2, 2.1, 2.2...

The maximum length of the workbooks will be 40 pages.

The first time an abbreviation is used in the text will be specified first complete equivalence and then stands.

\section{Front cover:}

Title:

Font size 14, centered, Bold.

Author name(s):

Font size 12.

Abstract:

It should include abstract in Spanish and abstract (font size 10), no more than 250 words.

Keywords:

Include three to five keywords, in Spanish and English.

Reference of author:

Institution of affiliation, academic degree and line-developed by research groups and belonging.

\section{Bibliographical appointment system:}

Harvard-APA

Citations in the text should include between parentheses only the author's name, publication date and page number, for example:

(Quilodrán, 2001: 33).

\section{Notation about Bibliography section and Information fonts:}

Should be included at the end of the text. All references must be mentioned in the text or footnotes page.

Each reference starts with the first name or last name, then the name of the author, and then, in parentheses, the year of publication followed by a period. Examples:

Article:

Ros, Jaime (2008). “La desaceleración del crecimiento económico en México desde 1982”, en Trimestre Económico, vol. 75, núm. 299, pp. 537-560.

Book:

Villarreal, René (2005). Industrialización, competitividad y desequilibrio externo en México. Un enfoque macroindustrial y financiero (1929-2010), México, Fondo de Cultura Económica.

Book chapter:

Castillo, Manuel Ángel (2003). "La política de inmigración en México: un breve recuento”, en Manuel Ángel Castillo, Alfredo Lattes y Jorge Santibáñez (coords.), Migración y fronteras, Tijuana, E1 Colegio de la Frontera Norte / Asociación Latinoamericana de Sociología / El Colegio de México, pp. 425-451. 


\section{Footnotes:}

Must be used to make additional indications, clarification or expansion of an explanation. The footnotes must be in Times New Roman, font size 10.

\section{Image typology inside text:}

Picture

Graph

Diagram

Map

Figure

All images must be numbered and mentioned in the text, should include the source image. The indications of the image: type and number of image, image title and source are written in 10 font size. In the text set as image maps, figures, graphs and charts-with the intention of not losing the formatting by the author.

\section{Equations and Formulae:}

When using equations or formulas should be used in Microsoft Word equation editor and numbered.

\section{Paper sending}

Entries must be sent to the email address: lgtz@uacj.mx. With Dr. Luis Enrique Gutiérrez Casas, editor of this publication.

Acceptance of each collaboration will depend on the evaluation of two examiners skilled in the art to be kept anonymous, like the author(s) for the same purposes. 


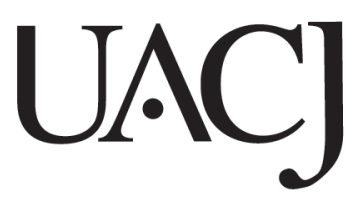

Esta obra se terminó de imprimir en abril de 2018 Cd. Juárez, Chihuahua, México.

Tiraje: 120 ejemplares 
Cuadernos de Trabajo de la Universidad Autónoma de Ciudad Juárez, número 45, mayo - junio de 2018

\section{Director y editor}

Dr. Luis Enrique Gutiérrez Casas

\section{Comité editorial}

Sección internacional

Dra. Sofía Boza Martínez (Universidad de Chile, Chile)

Dra. Olga Biosca Artiñano (Glasgow Caledonian University, Reino Unido)

Dra. Ángeles Sánchez Díez (Universidad Autónoma de Madrid, España)

Dr. Thomas Fullerton Mankin (University of Texas at El Paso, Estados Unidos)

Dr. Adrián Rodríguez Miranda (Universidad de la República, Uruguay)

\section{Sección local}

(Universidad Autónoma de Ciudad Juárez)

Dra. Myrna Limas Hernández

Dra. Ikuho Kochi

Dr. Raúl Alberto Ponce Rodríguez

Dr. Isaac Leobardo Sánchez Juárez

Dr. Héctor Alonso Barajas Bustillos

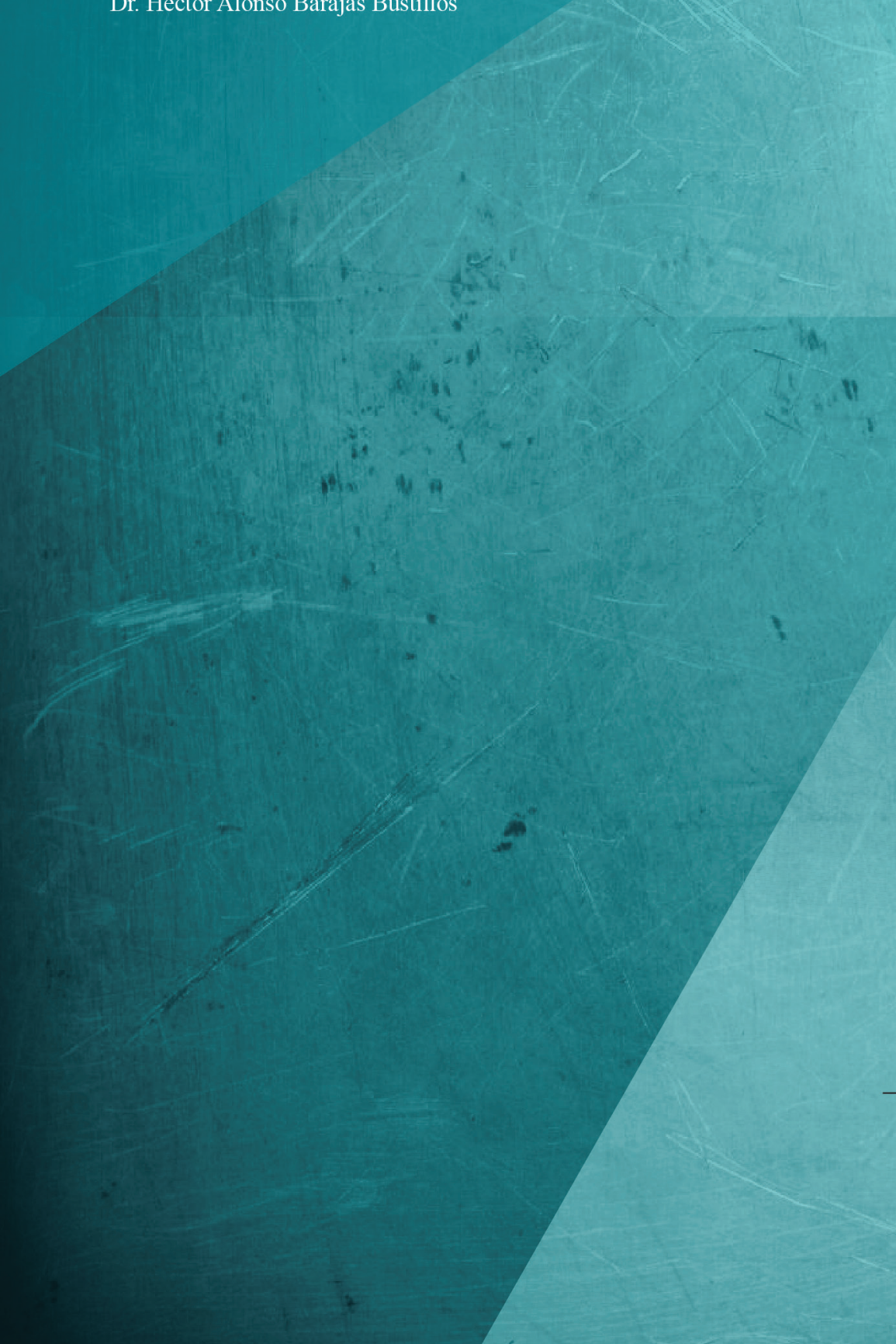

Universidad Autónoma de Ciudad Juárez Instituto de Ciencias Sociales y Administración Cuadernos de Estudios Regionales en Economía, Población y Desarrollo ISSN 2007-3739

Cuerpo Académico de Estudios Regionales en Economía, Población y Desarrollo

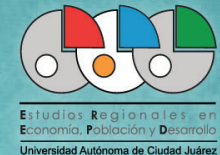

www.estudiosregionales.mx

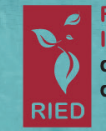
Iberoamericana
de Estudios del Desarrollo

Publicación afiliada a la Red Iberoamericana de Estudios del Desarrollo

(c) Universidad Autónoma de Ciudad Juárez Avenida Plutarco Elías Calles \#1210, Fovissste Chamizal Ciudad Juárez, Chih., México. www.uacj.mx 